\title{
Can Water Vapour Raman Lidar Resolve Profiles of Turbulent Variables in the Convective Boundary Layer?
}

\author{
Volker Wulfmeyer · Sandip Pal • David D. Turner • \\ Erin Wagner
}

Received: 21 July 2009 / Accepted: 25 March 2010 / Published online: 8 May 2010

(C) The Author(s) 2010. This article is published with open access at Springerlink.com

\begin{abstract}
High-resolution water vapour measurements made by the Atmospheric Radiation Measurement (ARM) Raman lidar operated at the Southern Great Plains Climate Research Facility site near Lamont, Oklahoma, U.S.A. are presented. Using a 2-h measurement period for the convective boundary layer (CBL) on 13 September 2005, with temporal and spatial resolutions of $10 \mathrm{~s}$ and $75 \mathrm{~m}$, respectively, spectral and autocovariance analyses of water vapour mixing ratio time series are performed. It is demonstrated that the major part of the inertial subrange was detected and that the integral scale was significantly larger than the time resolution. Consequently, the major part of the turbulent fluctuations was resolved. Different methods to retrieve noise error profiles yield consistent results and compare well with noise profiles estimated using Poisson statistics of the Raman lidar signals. Integral scale, mixing-ratio variance, skewness, and kurtosis profiles were determined including error bars with respect to statistical and sampling errors. The integral scale ranges between 70 and $130 \mathrm{~s}$ at the top of the CBL. Within the CBL, up to the third order, noise errors are significantly smaller than sampling errors and the absolute values of turbulent variables, respectively. The mixing-ratio variance profile rises monotonically from $\approx 0.07$ to $\approx 3.7 \mathrm{~g}^{2} \mathrm{~kg}^{-2}$ in the entrainment zone. The skewness is nearly zero up to $0.6 z / z_{i}$, becomes -1 around $0.7-0.8 z / z_{i}$, crosses zero at about $0.95 z / z_{i}$, and reaches about 1.7 at $1.1 z / z_{i}$ (here, $z$ is the height and $z_{i}$ is the CBL depth). The noise errors are too large to derive fourth-order moments with sufficient accuracy. Consequently, to the best of our knowledge, the ARM Raman lidar is the first water vapour Raman lidar with demonstrated capability to retrieve profiles of turbulent variables up to the third order during daytime throughout the atmospheric CBL.
\end{abstract}

Keywords Boundary-layer turbulence - Convective boundary layer · Raman lidar . Turbulence statistics

V. Wulfmeyer $(\varangle) \cdot$ S. Pal

Institute of Physics and Meteorology, University of Hohenheim, Stuttgart, Germany

e-mail: volker.wulfmeyer@uni-hohenheim.de

URL: www.uni-hohenheim.de/www120

D. D. Turner · E. Wagner

Atmospheric and Oceanic Sciences Department, University of Wisconsin-Madison, Madison, WI, USA 


\section{Introduction}

Water vapour is a key meteorological variable and plays an important role in governing the thermodynamic state of the atmosphere in various regimes starting from very small scales to the synoptic scale. The distribution of water vapour in the atmosphere influences various processes, e.g., radiative transfer, evapotranspiration, the stability of the lower troposphere, entrainment, convection initiation, and cloud formation (Browning and Gurney 1999; Weckwerth et al. 1999; Weckwerth 2000; Wulfmeyer et al. 2008). Consequently, studies dealing with both vertical and horizontal water vapour transport processes in the lower troposphere are of the utmost importance for improvements of land-surface and atmospheric numerical models. Measurements of higher-order moments of moisture variability yield unique estimates of turbulence in the convective boundary layer (CBL). Water vapour variance is used as a key parameter in many turbulence, convection, and cloud parameterizations (e.g., Tompkins 2002; Berg and Stull 2005; Gustafson and Berg 2007).

The water vapour mixing ratio is a conserved variable (in the absence of condensation and evaporation), and thus it is a good tracer of atmospheric motion. The variance profile can also be used to identify the mean CBL height. Vertical distributions of water vapour skewness and kurtosis change their patterns during different phases of the CBL evolution depending on the interaction among various convective scales. Particularly, entrainment processes at the top of the CBL control the vertical transport of humidity in the free troposphere, which depends on the strength of the temperature inversion as well as the wind shear profile and the presence of gravity waves (Mahrt 1991; Sorbjan 1996; Sullivan et al. 1998).

During the last two decades, there have been many efforts to study turbulent transport processes in the atmosphere using different methodologies and instruments. In-situ turbulence measurements have been used for many years to study the turbulent structure of the CBL (e.g., Lenschow and Kristensen 1985). However, remote sensing techniques such as lidar and radar systems have reached the resolution and accuracy to enable profiles of turbulent variables to be measured through the lower troposphere (e.g., Kropfli 1986; Eberhard et al. 1989; Angevine et al. 1993; Cohn 1995; Frehlich and Cornman 2002; Hogan et al. 2009). The major advantage in the application of these remote sensing techniques lies in the simultaneous investigation of turbulence properties from the surface layer to and through the entrainment zone. In particular, the entrainment zone of the CBL is generally much higher than can be sampled with meteorological towers, and sampling of entrainment by soundings and aircraft in-situ measurements is very difficult and expensive. Furthermore, remote sensing approaches allow for more regular and routine sampling of the CBL structure. Therefore, there is large interest in CBL studies using ground-based remote sensing systems.

Accurate, low-noise, high-resolution remote sensing measurements of water vapour mixing ratio can be used to investigate turbulence in the CBL. To date, only differential absorption lidar (DIAL) has demonstrated the resolution and accuracy required for turbulence measurements (Senff et al. 1994; Kiemle et al. 1997; Wulfmeyer 1998, 1999a,b; Wulfmeyer and Bösenberg 1998; Giez et al. 1999; Kiemle et al. 2007). Recently, high-resolution lidar measurements have also been applied to comparisons with large-eddy simulation (LES) of the CBL (Wulfmeyer 1999b; Couvreux et al. 2005). In the future, active remote sensing systems may even be able to determine three-dimensional water vapour fields (Wulfmeyer and Walther 2001a,b).

Previously, a scanning, solar-blind Raman lidar system operating at $248 \mathrm{~nm}$ (Eichinger et al. 1999) was used for daytime turbulence measurements in the surface layer (e.g., Eichinger 
et al. 2000, 2006; Cooper et al. 2003). However, due to the limited range of this system (a few $100 \mathrm{~m}$ ) caused by ozone absorption in this wavelength range, measurements up to the CBL top are not possible resulting in very limited information about entrainment processes. In contrast, Raman lidar systems operating at $355 \mathrm{~nm}$ are capable of water vapour measurements up to the middle troposphere even during daytime. Mecikalski et al. (2006) used 1- min Raman lidar mixing ratio data to investigate coherent structures such as horizontal rolls in the boundary layer; however, high-resolution measurements for turbulence profiling have not been analyzed to date.

A major advancement in the study of CBL turbulence based on lidar measurements came through the pioneering work of Lenschow et al. (2000) (LE2000 in the following). They introduced a straightforward approach to measuring higher-order moments in noisy data based on a detailed error analysis. The methodology was applied to high-resolution water vapour DIAL and Doppler lidar vertical velocity measurements. Following this procedure, Wulfmeyer and Janjić (2005) successfully derived the profiles of higher-order moments of vertical velocity fluctuations obtained from ship-borne Doppler lidar in the tropical Pacific Ocean during a full diurnal cycle of the marine CBL.

Raman lidar systems also have the capability of measuring water vapour mixing ratio at high temporal and spatial resolutions (e.g., Turner and Goldsmith 1999; Whiteman et al. 2006; Ferrare et al. 2006). However, the following question arises: is the accuracy and resolution of state-of-the-art water vapour Raman lidar systems sufficient to derive higher-order moments of turbulence in the boundary layer?

The data used in the present study were obtained at the Atmospheric Radiation Measurement (ARM) Southern Great Plains (SGP) Climate Research Facility (ACRF) site near Lamont, Oklahoma, U.S.A. with its Climate Research Facility (CRF) water vapour Raman lidar CARL (see Goldsmith et al. 1998 for a detailed description of the lidar). This study is timely, as near-range measurements of CARL were recently improved by the incorporation of advanced detection electronics that combine analogue-to-digital and photon counting into a single package (Newsom et al. 2009). CARL is an operational water vapour remote sensing system, operating for $90 \%$ of the time following an electronics upgrade in September 2004; therefore, if turbulence profiles can be retrieved with acceptable accuracy, routine measurements of the turbulent properties of the atmospheric boundary layer (ABL) become possible.

Our goal is to provide a detailed characterization of CARL measurements to determine if indeed turbulence profiles can be observed in the CBL. For this purpose, we apply the methodology of LE2000 to CARL mixing ratio measurements. We derive vertical profiles of the higher-order moments of water vapour mixing ratio $m$ up to the fourth order together with the detailed error estimations. We also determine higher-order moments of system noise, which give further insight into the quality of CARL mixing-ratio measurements.

The paper is organized in seven sections: an overview of the experiment with a brief description of the measurement site and of CARL is given in Sect. 2. The meteorological conditions during the measurement selected for turbulence analyses are discussed in Sect. 3. After the presentation of time-height cross-sections of aerosol scattering ratio and mixing ratio during the measurement period of interest in Sect. 4, Sect. 5 discusses the methodology for turbulence analyses and the resulting profiles of higher-order moments of mixing ratio including a thorough error analysis. In Sect. 6, the structures of the turbulent profiles and their relation to turbulent transport and exchange processes are discussed. The conclusions and an outlook are given in Sect. 7 . 


\section{CARL System}

CARL is a fully autonomous Raman lidar system that is capable of measuring profiles of water vapour mixing ratio, aerosols, and clouds throughout the diurnal cycle for the ARM program (Goldsmith et al. 1998). It is located at the ARM CRF site close to Lamont, Oklahoma $\left(36.6^{\circ} \mathrm{N}, 97.5^{\circ} \mathrm{W}\right)$. The environment is characterized by flat terrain and rather heterogeneous land-surface properties.

CARL transmits pulses of linearly polarized $355-\mathrm{nm}$ radiation into the atmosphere at $30 \mathrm{~Hz}$, and collects the backscattered energy with a $0.61-\mathrm{m}$ telescope. The incoming light is split into two different fields-of-view (FOV) with 2 and $0.3 \mathrm{mrad}$ FOV angles, respectively. Both FOV s together provide good sensitivity both in the near- and far-ranges. In each FOV, the light is separated into signals associated with the Raman scattering of water vapour ( $408 \mathrm{~nm}$ ) and nitrogen $(387 \mathrm{~nm})$ as well as the elastic return at the laser wavelength. The narrow FOV elastic return is separated into both the co- and cross-polarization components with respect to the polarization of the outgoing laser beam. The original system configuration utilized photon-counting electronics in these seven channels, with a maximum resolution of $1 \mathrm{~min}$ and $39 \mathrm{~m}$.

Automated routines were developed to process these backscatter signals to derive profiles of water vapour mixing ratio, relative humidity, aerosol backscatter coefficient and extinction coefficient, as well as the linear depolarization ratio (Turner et al. 2002). The water vapour mixing ratio is determined from the ratio of two Raman backscatter signals, the water vapour Raman channel at $408 \mathrm{~nm}$ and the nitrogen Raman channel at $387 \mathrm{~nm}$. This ratio is multiplied by several height-dependent correction factors resulting in a signal that is proportional to mixing ratio (e.g., Whiteman et al. 1992; Turner and Goldsmith 1999). These height-dependent correction factors include accounting for the differential transmission due to molecules and aerosols in the water vapour $(408 \mathrm{~nm})$ and nitrogen $(387 \mathrm{~nm})$ channels, and an "overlap correction" that accounts for the slight misalignment of the telescope with the outgoing laser beam. The overlap correction, which becomes negligible at some height above the telescope, is a static correction and in general does not change with time; thus any errors in the specification of this correction translate into a small bias in the derived water vapour profile.

The final step in the processing of the water vapour mixing ratio is the application of a height-independent calibration factor to the ratio of the backscattered profiles. In theory, this factor could be derived from first principles (e.g., Sherlock et al. 1999). However, due to the uncertainty in the Raman cross-sections and the transmission of the optics in CARL, the ARM program calibrates the lidar such that the integrated water vapour agrees with that retrieved from a two-channel microwave radiometer (Turner and Goldsmith 1999). Using these techniques, comparisons with other water vapour sensors have demonstrated high accuracy with water vapour Raman lidar measurements in the field (Behrendt et al. 2007a,b). Furthermore, if the overall bias is time independent, it does not influence the accuracy of profiles of turbulent moments.

In September 2004, the detection electronics were replaced with new electronics that incorporate both photon counting and analogue-to-digital detection into the same package (Turner and Goldsmith 2005). A key component of the processing is the 'merging' of the photon-counting and analogue-to-digital data from a given channel into a signal profile for that channel that is then used in the subsequent processing into geophysical variables (Newsom et al. 2009). These new electronics greatly improved the signal-to-noise ratio (SNR) in the various channels by increasing the dynamic range of the instrument, thereby allowing some neutral density attenuating filters, which were needed to prevent the system from saturating the original photon counting electronics, to be removed. The increase in SNR improved both 
the maximum range and the accuracy of the derived products (Ferrare et al. 2006). These new electronics improved the maximum resolution of the data to $10 \mathrm{~s}$ and $7.5 \mathrm{~m}$. More importantly, the new electronics allowed the elimination of the separate daytime and nighttime modes that were used previously (Turner and Goldsmith 1999), and thus the same calibration could be used for the entire diurnal cycle. This has resulted in the daytime and nighttime differences in water vapour mixing ratio with calibrated radiosondes to be smaller than $1 \%$ (Newsom et al. 2009).

\section{Meteorological Conditions}

For our study, we selected a dataset from 2000 to 2200 UTC, 13 September 2005, and studied the meteorological conditions using the analyses of the European Centre for MediumRange Weather Forecasting (ECMWF). During this day, a long-wave trough dominated the large-scale synoptic situation over the northern central USA and south-central Canada. (Another striking feature was hurricane Ophelia, which was located near the east coast of the US.) Embedded in the long-wave trough, a short-wave trough over Nevada and Idaho guided two jet streaks at $300 \mathrm{hPa}$ with a north-westerly wind direction over Canada and a south-westerly wind direction over the central US, respectively, which merged in the Great Lakes region (not shown). The short-wave trough was associated with a pool of colder air in the middle troposphere that was located around Wyoming during the time of interest.

In contrast, Mexico and the southern USA were influenced by a large high pressure system. Consequently, Oklahoma with its ACRF SGP site was located in a transition zone between these large-scale synoptic features. This transition zone, which separated dryer and colder air over the western USA from moist air transported from Mexico over Texas into southeastern Oklahoma, was visible in the humidity field as well as in the wind field from the 500-hPa level down to the ground. Because the humidity gradient and the region of wind rotation were relatively sharp, we can identify this transition as a cold front or dryline. For instance, Fig. 1 presents analyses of the $850-\mathrm{hPa}$ geopotential (white lines), the specific humidity, and the horizontal wind vector at 1800 UTC and 2400 UTC. Clearly, the location of the front stretching from south-west to north-east over the Oklahoma panhandle can be identified.

For our studies, the development of the frontal zone from ground to a height of about $3.5 \mathrm{~km}$ was of particular interest. Figure 1 demonstrates that the dryline was more or less stationary from 1800 to 2400 UTC so that the ACRF SGP site remained on the moist side of the dryline. Only a slight change in wind direction from south-west to south, and some moistening of the lower troposphere from 10 to $13 \mathrm{~g} \mathrm{~kg}^{-1}$ due to pockets of moist air embedded in the flow, were expected. At the surface, a similar picture existed. The dewpoint difference clearly identified that the dryline was located slightly east of the Oklahoma panhandle and remained nearly stationary. A similar change in wind direction from south-west to south at $850 \mathrm{hPa}$ was analyzed without a considerable change in surface moisture (not shown). Thus, during the time of the measurement, the synoptic influence on the meteorological conditions at the site remained weak. During daytime, a well-mixed convective boundary layer developed, which was barely influenced by mesoscale features. This makes the determination and interpretation of the first Raman lidar turbulence measurements easier, and were the main reasons for selecting this dataset.

Figure 2 presents the observed meteorological conditions at the measurement site. Meteorological mean values such as mixing ratio at 2 and $60 \mathrm{~m}$, precipitable water vapour, and wind 

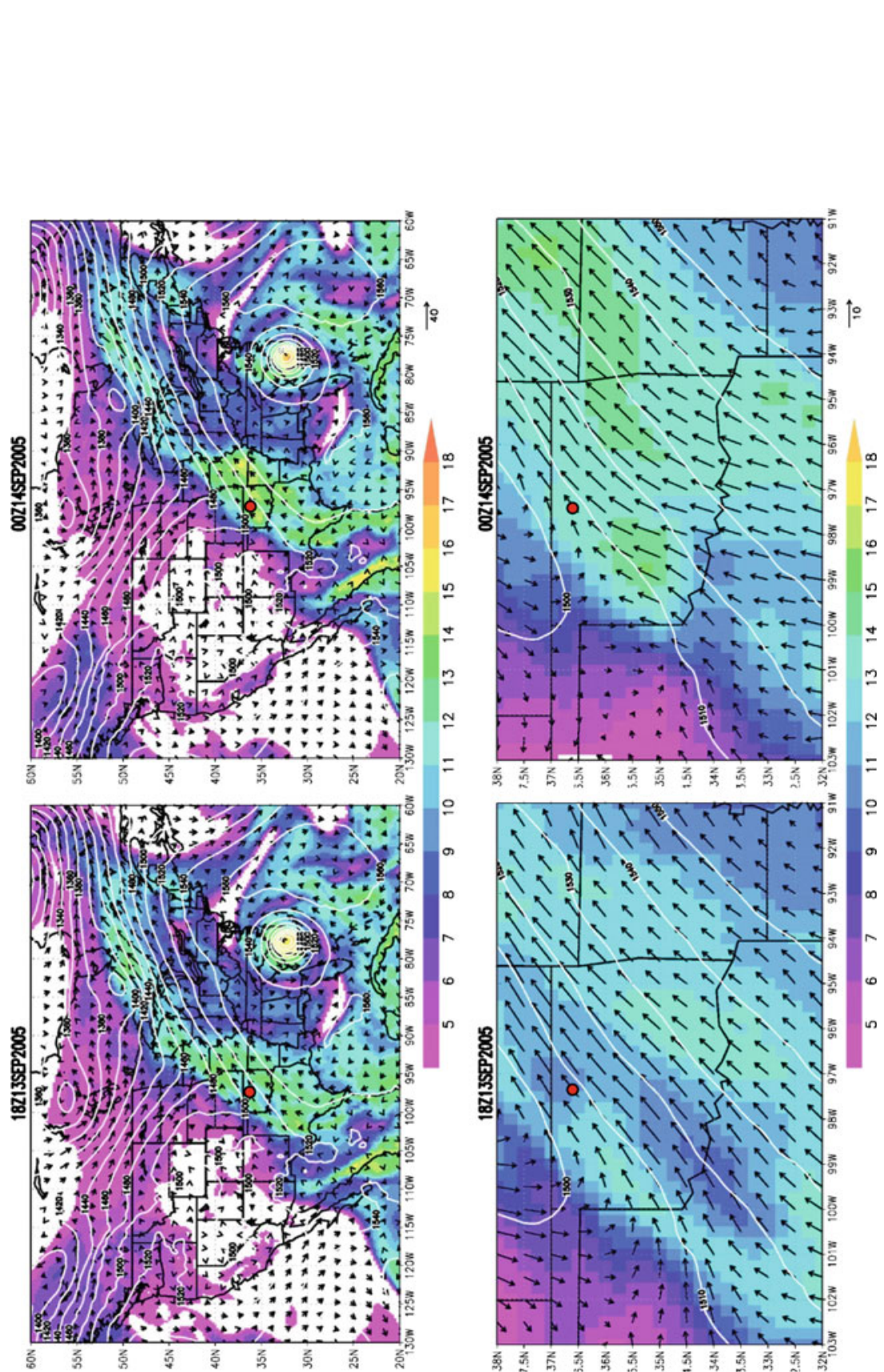

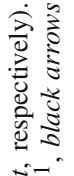

$\stackrel{5}{\approx 0100}$

苗.

过:

$\cup$

S记

ஓ융

हैं

$\pm \infty$

$=\quad \overline{0} \frac{\tilde{\Xi}}{\tilde{z}}$

- 䒕 引

$\simeq$ ธี.

\pm 芩

บ

$8 \underset{0}{0}$

11 11 1 का

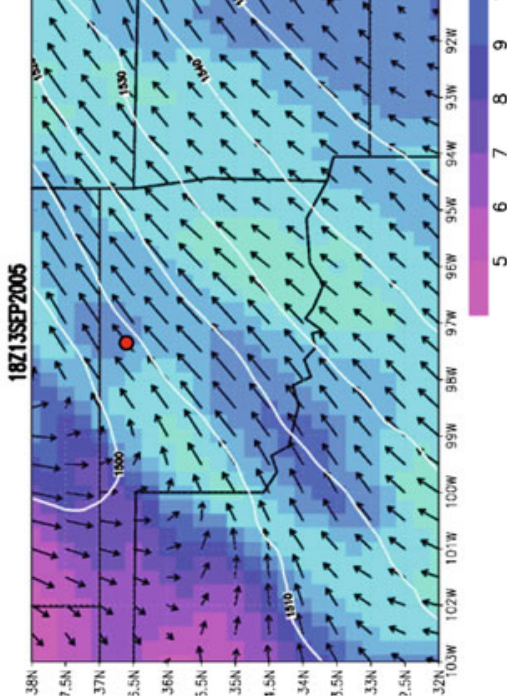

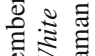

党

ฝे ॐำ

긍

ㅎํํํํำ

\& च

芯氞

เ ฐี

$\sum_{0}^{N} \tilde{a}$

可㐫

ป ะญ

ర్

ส

की

:气气

ᄋ 0

:

응 专

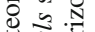

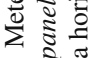

- ذँ

ำ 


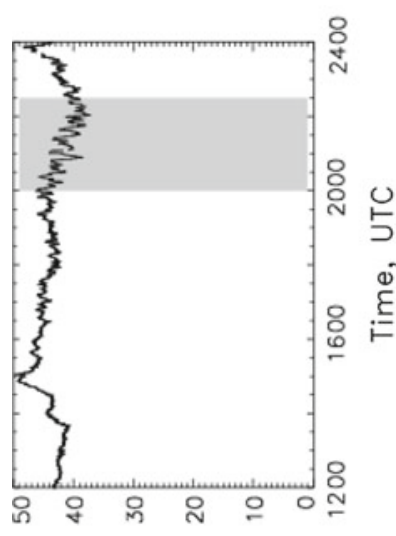

$[z \omega / 6 x] M M d$

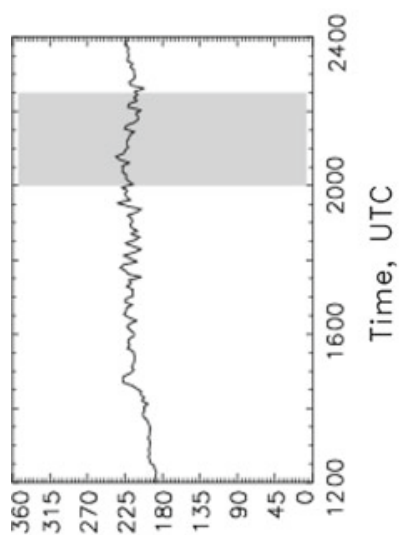

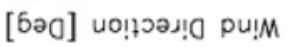

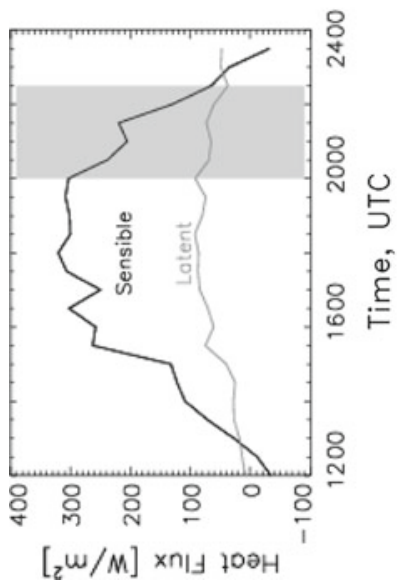

造要

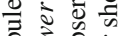

焉亭

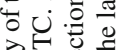

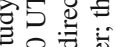

o 원

동

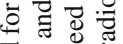

व 8 के

얼

政

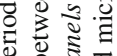

\% छ

政

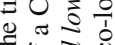

至

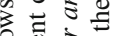

的施

n 형용

要

2 记 $\Xi$ on

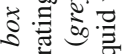

吕论

을

in $x$

额

要远

政

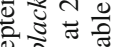

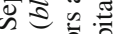

mo

的它

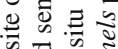

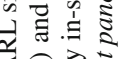

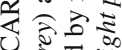
过 言 咩 응

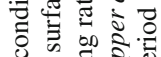
당 5 कo. 응 政

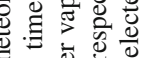
可

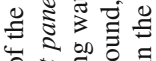
o 10 굴 을 궁 웅 은 ठิ5 人

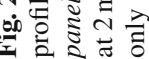


direction did not change significantly during this day indicating weak advection. Latent and sensible heat fluxes were measured at the site using the eddy-correlation technique with a sonic anemometer (Gill Solent Windmaster Pro) in combination with an infrared gas analyser (Licor Inc. LI-7500). The sensible heat flux confirmed the development of a CBL starting at about 1300 UTC; from 1600 to 2200 UTC, the sensible heat flux remained positive and reached a maximum of about $300 \mathrm{~W} \mathrm{~m}^{-2}$ around 1800 UTC. The latent heat flux was rather small and barely reached $100 \mathrm{~W} \mathrm{~m}^{-2}$ at $1800 \mathrm{UTC}$, indicating a low amount of soil moisture, consistent with local soil moisture measurements.

For the first turbulence analyses with CARL we selected a period that included cumulus clouds in the CBL, and gave us the opportunity to investigate whether our methodology for determining turbulence profiles can also be applied during conditions where the CBL is topped with clouds. This is an important issue for the development of a long-term database of turbulent variables, as an effect of clouds on turbulent exchange processes in the entrainment zone can be expected.

We studied the presence of CBL clouds with cloud liquid and lidar backscatter measurements (see Fig. 2, lower right panel). Since boundary-layer clouds affected the initial time period when the CBL developed and reached a quasi-stationary state, the time period from 2014 to 2214 UTC was selected for the first CARL turbulence studies (marked by a grey bar in Fig. 2). During this period, the boundary-layer depth was sufficiently constant, data gaps were sufficiently small, and the time series was sufficiently long so that a detailed and accurate analysis of turbulence profiles was possible.

\section{Analysis of CARL Backscatter and Mixing-Ratio Measurements}

\subsection{Determination of Boundary-Layer Structure and Depth}

Figure 3 presents the time-height cross-section of the aerosol scattering ratio (ASR) $A$ derived from the narrow field-of-view CARL observations on 13 September 2005 from 1200 to 2400 UTC with resolutions of $75 \mathrm{~m}$ and $10 \mathrm{~s}$, respectively. The ASR was computed following the procedure in Whiteman et al. (1992) using the modifications provided in Turner et al. (2002). Data below $500 \mathrm{~m}$ above ground are not shown, as these were affected by systematic errors due to incomplete overlap between transmitter and receiver. [The wide FOV would be able to provide data in this lowest region of the atmosphere; however, the signal-to-noise ratio is much lower than the narrow FOV. This large difference in the signal-to-noise ratio, especially where the two FOVs were merged together, would have challenged the analysis, and thus we used data only from the narrow FOV.] Vertical black bars are due to data gaps and white areas indicate an overload of the detector or out of range values due to the presence of clouds. ASR data are essential for the detection of cloud bottoms (and tops if the cloud optical thickness is sufficiently low) and for determining the time series of the instantaneous ABL depth $z_{i}$. This is an important scaling variable for turbulence profiles (see Sect. 5).

During the whole measurement period, ASR in non-cloudy regions ranged from 1 to about 2.5. Aerosol layers were identified by larger ASR values, as pure molecular backscattering is characterized by $A=1$. During 1200-1400 UTC, the near-range data of CARL showed a shallow boundary layer. At 1500 UTC, first indications of enhanced vertical mixing of aerosols became visible. However, between 1500 and 1700 UTC, the expected evolution of the CBL was disturbed by complex advective and vertical mixing processes. From 1700 UTC on, the evolution of the CBL was evident by the development of a strong ASR gradient at the top of the CBL with a height of about $1200 \mathrm{~m}$. This gradient occurs since, generally, the 


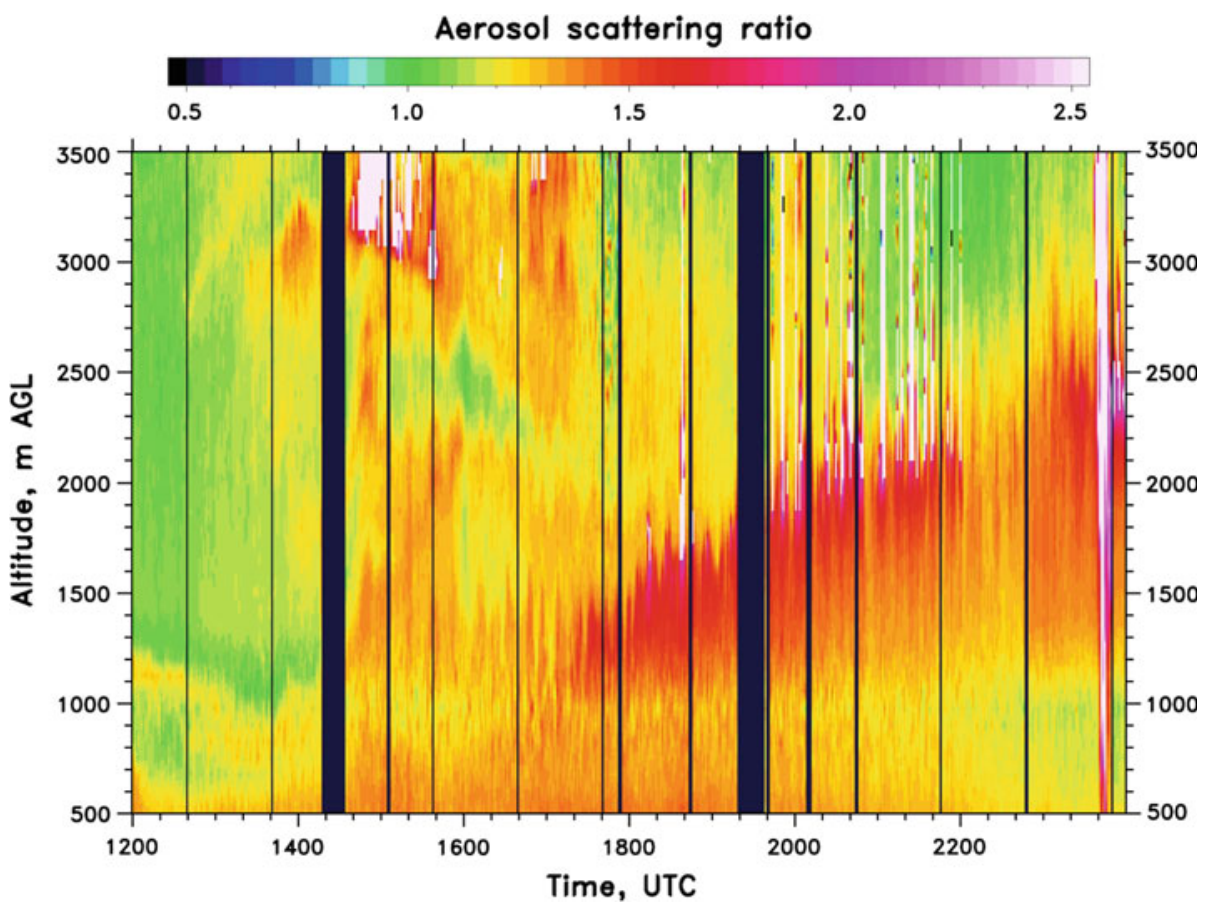

Fig. 3 Time-height cross-section of aerosol scattering ratio during 13 September 2005 measured with resolutions of $10 \mathrm{~s}$ and $75 \mathrm{~m}$, respectively. The evolution of the CBL with imbedded clouds can be detected from 1600 to 2200 UTC. Vertical black bars indicate temporal gaps in the data. White areas show overloaded or out-of-range values due to clouds, some black pixels above clouds are due to detector ringing

strongest sources of aerosol particles are located at the surface and these are vertically mixed throughout the CBL. Simultaneously, the particle backscatter coefficient can be increased by aerosol swelling if the relative humidity exceeds about 80\% (Wulfmeyer and Feingold 2000; Pahlow et al. 2006). This effect is particularly visible in Fig. 3 below clouds. Starting at about 1900 UTC, ASR values above 2.5 indicated the development of boundary-layer clouds close to the top of the CBL.

The CBL reached a nearly constant level with low cloud coverage between 2014 and 2214 UTC, and a detailed overview of the CBL structure is presented in Fig. 4. Boundary-layer clouds developed with bases at a height of $\approx 2000 \mathrm{~m}$. Below these clouds, aerosol swelling produced a strong increase in ASR of more than a factor of two. Regions of relative humidity greater than $80 \%$ extend about $500 \mathrm{~m}$ below the cloud bases.

Clouds influenced the determination of $z_{i}$, since sampling errors are introduced where the algorithm was not applicable. For instance, if the signal was still evaluated inside the clouds, the strong attenuating of the backscatter signal led to an underestimation of the cloud top, which should be used for the instantaneous $z_{i}$. If the signals cannot be analysed due to detector overload, the omission of the determination of $z_{i}$ produces a sampling error also resulting in a negative bias. We did not make an attempt to determine the resulting bias, as this becomes only important if detailed comparisons with profiles of similarity relationships or LES are performed, which was not the subject of this work. Nevertheless, in order to measure $z_{i}(t)$, we applied the Haar wavelet analysis introduced in Davis et al. (2000), which was also used in Cohn and Angevine (2000) and in Wulfmeyer and Janjić (2005). Details of 


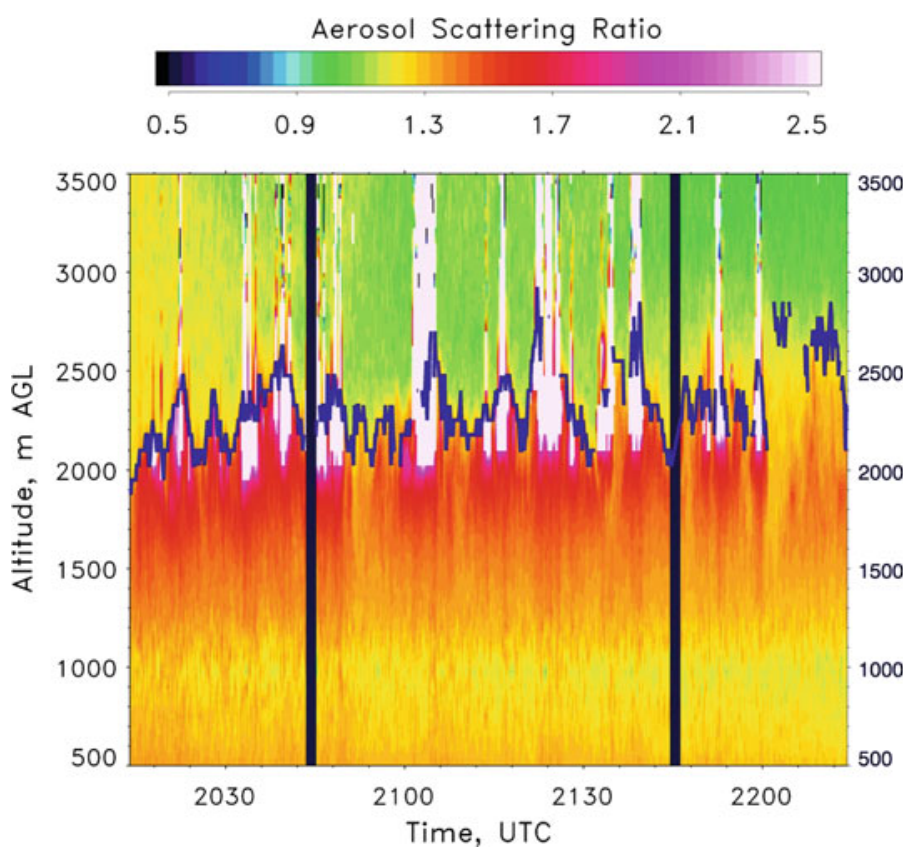

Fig. 4 Time-height cross-section of aerosol scattering ratio during the period of interest. Vertical black bars indicate small temporal gaps in the data. Swelling of aerosol particles due to increased relative humidity below clouds is visible. As the ASR is due to elastic backscatter signals, which are easily overloaded, it is very sensitive to the detection of boundary-layer cloud bottoms but the signals can be overloaded and prone to systematic errors inside the clouds. The blue line indicates the determination of $z_{i}$ using the wavelet analysis

this technique, as well as a discussion and confirmation of its accuracy, are presented in Pal et al. (2010). The resulting time series of $z_{i}$ is shown as an overlay in Fig. 4. A mean value of $\bar{z}_{i} \approx 2320 \mathrm{~m}$ with a standard deviation of $190 \mathrm{~m}$ was determined.

\subsection{Evolution of the Mixing-Ratio Field During the Observation Period}

Figure 5 depicts the 12-h observation of mixing ratio, with temporal and spatial resolutions of $\delta t=10 \mathrm{~s}$ and $\delta z=75 \mathrm{~m}$, respectively. For this analysis, we used only the narrow FOV data, and so the mixing-ratio data become reliable at a height $>500 \mathrm{~m}$ after correcting for the overlap. Vertical black bands on the image are the times when no data were available; other black and white areas indicate erroneous data due to low SNR that is typically caused by attenuation by clouds.

After sunrise at around 1215 UTC, the boundary layer became unstable and a growing CBL developed, which becomes visible in the height range covered by CARL at about 1500 UTC. During CBL growth, layers above were entrained into the CBL, which reached a depth of $2000 \mathrm{~m}$ around 2000 UTC. Figure 5 shows that between 1500 and 1800 UTC a distinct laminated dry layer at an altitude between 2.2 and $2.5 \mathrm{~km}$ was present with a mixing ratio $\approx 6.5 \mathrm{~g} \mathrm{~kg}^{-1}$. In the CBL, the mixing ratio reached values of about $18 \mathrm{~g} \mathrm{~kg}^{-1}$ at the top of the CBL. The difference in mixing ratio between the CBL value and the free troposphere varied from about $6 \mathrm{~g} \mathrm{~kg}^{-1}$ for the growing CBL to $13 \mathrm{~g} \mathrm{~kg}^{-1}$ for the well-developed CBL.

A high-resolution zoom in the mixing-ratio field from 2014 to 2214 UTC, our time period for turbulence analyses, is presented in Fig. 6. The determination of mixing ratio 


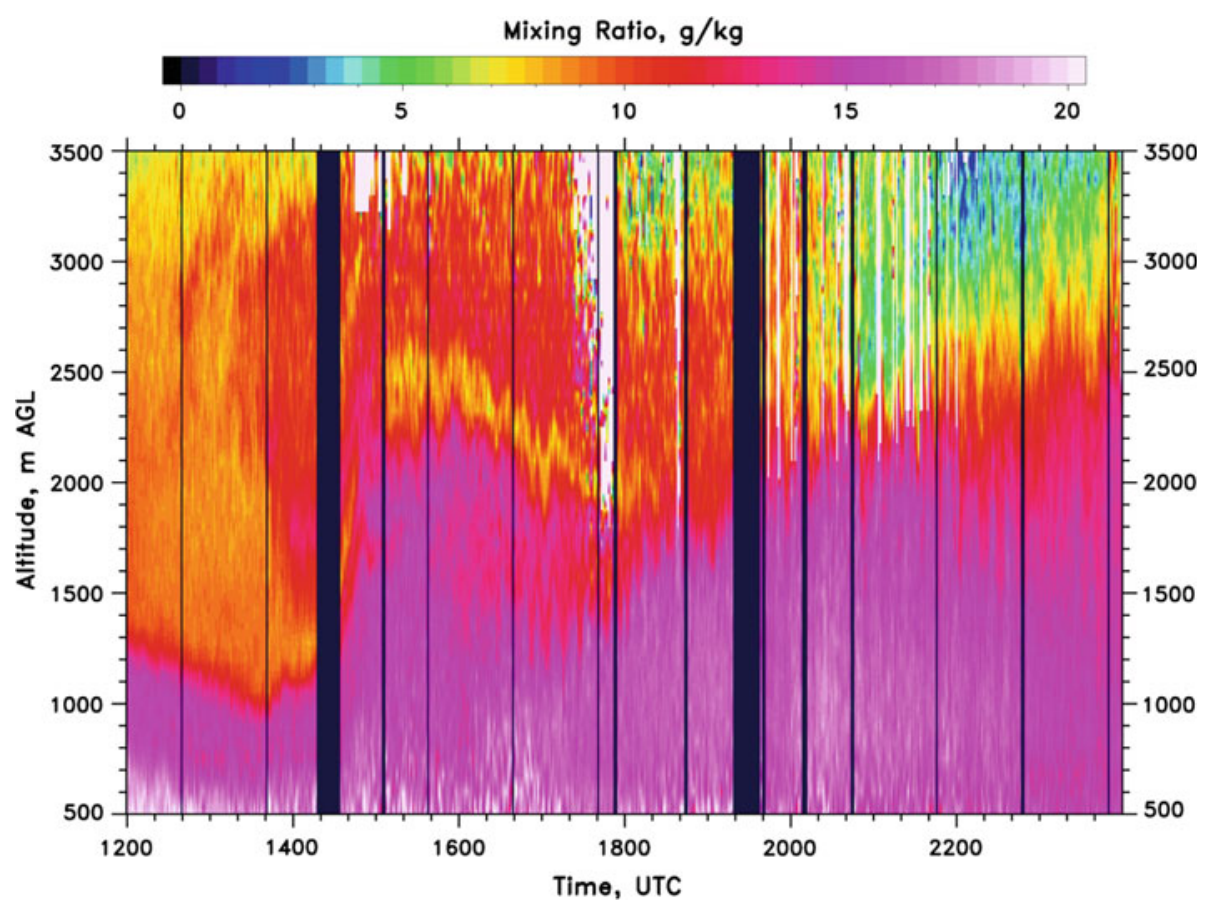

Fig. 5 Time-height cross-section of water vapour mixing ratio from the narrow field-of-view during 13 September 2005, with resolutions of $10 \mathrm{~s}$ and $75 \mathrm{~m}$, respectively. The same convention as in Fig. 3 is used with respect to the visualisation of data gaps and data in the region of clouds

$m$ is very consistent in the sense that, below clouds, $m$ is maximal. Here cloud development is due to moist updrafts that reach $100 \%$ relative humidity before they penetrate the CBL top. In several cases, the condensation level is reached in the CBL and clouds form typically at a height of $2200 \mathrm{~m}$. In contrast, downdrafts are characterized by the entrainment of dryer air in the CBL. Similar to Fig. 4, the CBL top is identified by a strong humidity gradient.

A striking difference between the $m$ and ASR data is the number of valid data in the region of clouds. Since the water vapour mixing-ratio determination is due to the ratio of two Raman signals, both of which have strong blocking of the backscatter at the laser wavelength (Goldsmith et al. 1998), the dynamic range of the signals is less than the elastic backscatter signals used in ASR so that the danger of detector overload is reduced. Therefore, it may be reasonable to use the humidity gradient at the top of the CBL for determining $z_{i}$. We applied the same wavelet algorithm as in Sect. 4.1 to the water vapour mixing-ratio profiles to estimate the CBL top; this is overlaid in Fig. 6. We determined a mean CBL depth of $2450 \mathrm{~m}$ with a standard deviation of $200 \mathrm{~m}$. As pointed out above, a slight negative bias may remain due to sampling errors in the presence of clouds. It is worth mentioning that the reduced sensitivity to artifacts from clouds in the Raman lidar's water vapour data may result in less sampling errors than when using a DIAL system, as the DIAL's retrieval is based on elastic backscatter signals.

A comparison of the $z_{i}$ time series and its statistics are shown in Fig. 7. The mean value was systematically higher when using $m\left(\bar{z}_{i, m}=2450 \mathrm{~m}\right)$ than when using $A$ $\left(\bar{z}_{i, A S R}=2320 \mathrm{~m}\right)$. This difference was mainly driven by the slightly different locations of the 


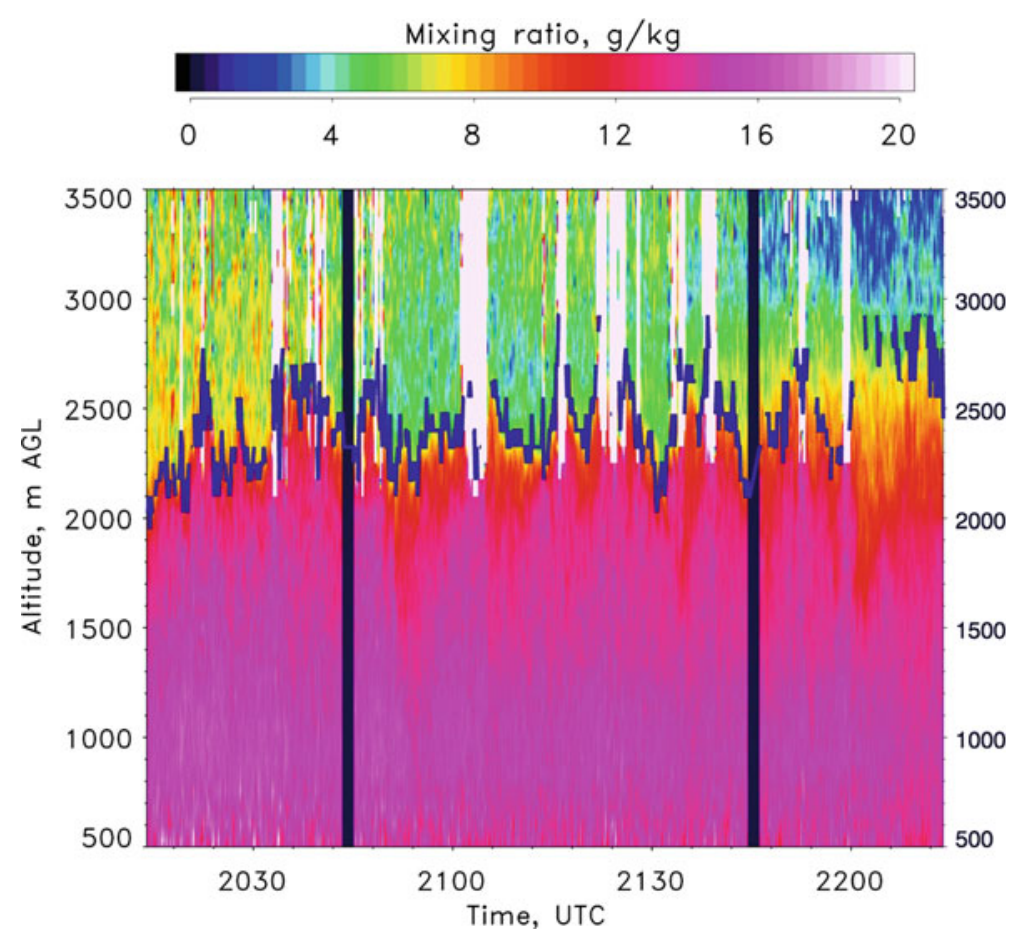

Fig. 6 Time-height cross-section of water-vapour mixing ratio from the narrow field-of-view during the same time period as shown in Fig. 4. The same convention as in Figs. 3, 4, and 5 is used with respect to the visualisation of data gaps, of data in the region of clouds, as well as of $z_{i}$ determined with the Haar wavelet. Near-range humidity up to $700 \mathrm{~m}$ is significantly affected by noise. The number of overloaded bins in the region of clouds is reduced in comparison to Fig. 4

maximum values in the gradients of $A$ and $m$ and not by the sampling errors, since the sampling errors only occurred in the relatively few cloudy profiles (resulting in an underestimation when using ASR). As the determination of CBL depth with the ASR gradient is a well-established technique and has demonstrated good accuracy when compared to other methods (Cohn and Angevine 2000; Pal et al. 2010), we applied $\bar{z}_{i, A S R}$ for CBL scaling.

\section{Retrievals of Higher-Order Moments of Mixing Ratio and Noise}

\subsection{Data Processing}

\subsubsection{Definitions}

In order to characterize the quality of mixing-ratio measurements, an accurate derivation of error profiles is critical. Systematic errors may be due to the inadequate correction for overlap and incorrect system calibration. However, since these can be considered time independent (Newsom et al. 2009; Turner and Goldsmith 1999), bias and low-frequency trends in the mixing ratio time series can be eliminated by suitable spectral filters before calculating 

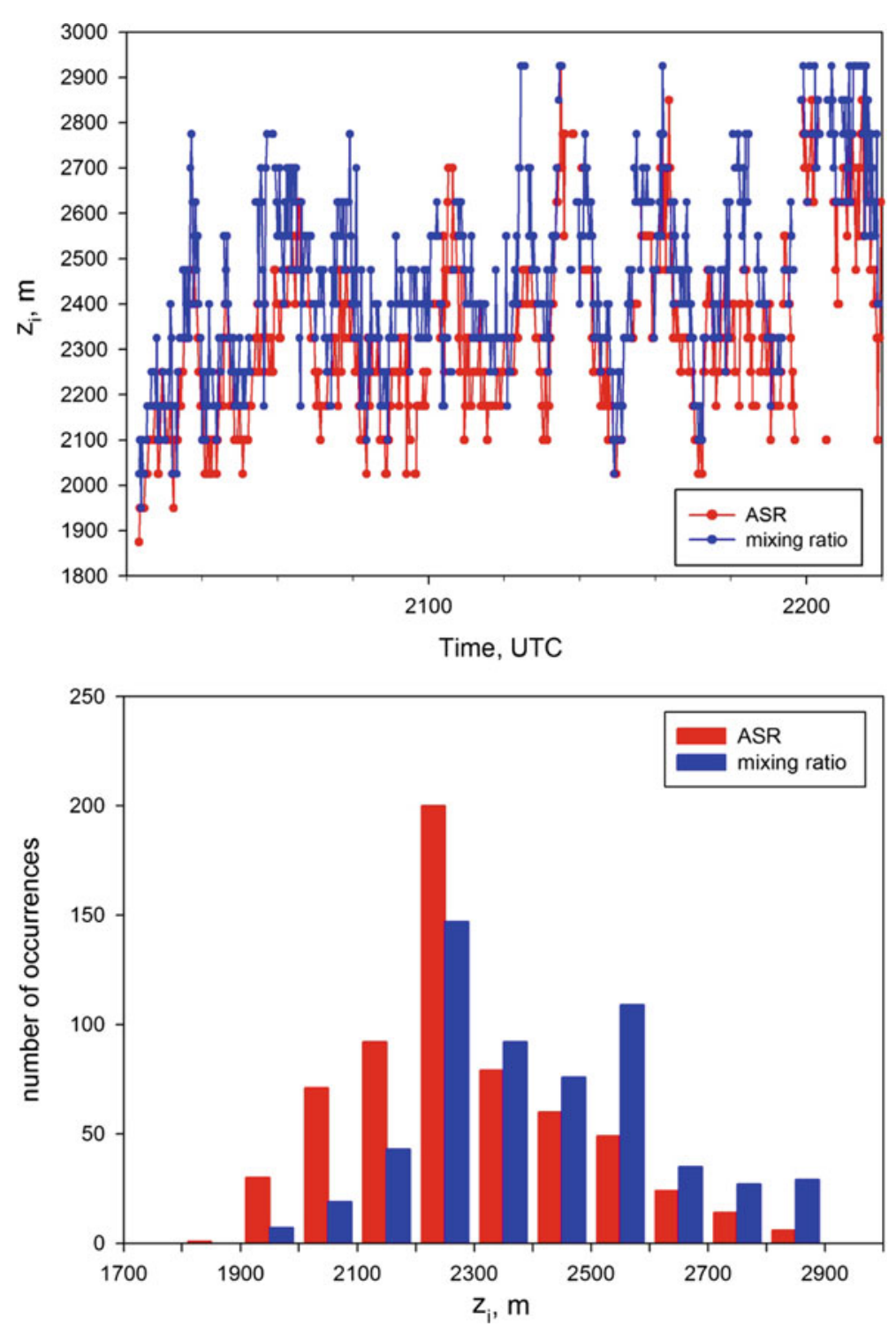

Fig. 7 Upper panel time series of $z_{i}$ determined by Haar-wavelet analyses applied to ASR (red) and $m$ (blue) fields. The resulting mixing-ratio depth is systematically larger for $\mathrm{m}$ by about $100 \mathrm{~m}$. Bottom panel corresponding histograms demonstrating a slightly skewed $z_{i}$ if ASR is used. The standard deviation is similar in both the ASR and $m$ and is approximately $200 \mathrm{~m}$

the mixing-ratio fluctuations. Thus, time-independent systematic errors do not influence the accuracy of turbulence profiles.

Before noise errors and higher-order moments are calculated, the mixing-ratio time series $m(t)$ has to be processed carefully. We define the measured mixing ratio $m$ as

$$
m(t)=\bar{m}(t)+m^{\prime}(t)+\varepsilon(t)
$$


where $\bar{m}(t)$ is a slowly varying trend of the time series. If the trend is negligible, $\bar{m}(t)=$ $\bar{m}=$ constant where $\bar{m}$ is the mean of $m(t), m^{\prime}(t)$ is the mixing-ratio fluctuation with zero mean, and $\varepsilon(t)$ is the system noise.

\subsubsection{Spike Removal}

Spikes in the time series are mainly due to non-linear effects in the mixing-ratio retrieval at very low SNR and in clouds. For the application presented in this study, in the range of interest up to $3500 \mathrm{~m}$, the SNR of the Raman signals was large so that spikes in the data were mainly due to the attenuation of the laser beam in the presence of clouds. Before further processing, these spikes have to be detected and flagged, as they negatively affect the calculation of turbulent variables. The influence of spikes in the time series becomes more severe for the higher moment calculations of the turbulent statistics.

The spike removal procedure is based on the technique introduced in Senff et al. (1996) and depends on three parameters: a temporal window width, a bin width, and a gap value. Within a gliding temporal window, a histogram is produced with the respective bin width. If, between two populated histogram bins, gaps are found that are larger than the prescribed gap-width variable, then all data points beyond the gap in the tail of the distribution are identified as spikes and removed.

We investigated carefully the sensitivity of the results as a dependence of the combination of these values. The length of the window is a compromise between the minimization of effects due to strong trends in the time series and the accuracy in the frequency distribution of mixing ratio values. In our case, trends were low so that the results were nearly independent of window width if the number of data points was larger than 30 (window width $>300 \mathrm{~s}$ ).

The bin width is a trade off between the resolution of the histogram and the separation and detection of spikes. Finally, the gap value should be set so that the noise and atmospheric variance of the time series are maintained and separated from spikes. In our algorithm, we set window width $=410 \mathrm{~s}$, bin width $=1.5 \mathrm{~g} \mathrm{~kg}^{-1}$, and gap $=5 \mathrm{~g} \mathrm{~kg}^{-1}$ at all heights. Using these values, spikes could clearly be identified by large separations between the fluctuating time series and its mean at all altitudes used in the analysis. Consequently, we expect remaining systematic errors to be negligible.

\subsubsection{Trend Removal}

It is assumed that variations in the time series due to mesoscale and synoptic processes and turbulence can be separated. This is reasonable as long as the scales causing turbulent fluctuations are much smaller. This may not be the case if small-scale mesoscale circulations are induced at the measurement site, which may be due to inhomogeneous land-surface properties (soil moisture, soil properties, vegetation, orography) or due to organized convection such as horizontal rolls. Perfect separation of turbulent and large scales was not the focus of this work; here we aim to characterize the CARL observations with respect to the determination of turbulence profiles and its dependence on system noise but not on scale separation issues.

In our 2-h analysis period, only weak low-frequency variations were found in the CARL time series at various heights. These were determined and removed by subtracting a linear fit to the time series at each height and subsequent high-pass filtering with a cutoff time of $30 \mathrm{~min}$. High-pass filtering was performed in frequency space by multiplying the Fourier transform with an appropriate filter function. More details can be found in 
Senff et al. (1996) and Wulfmeyer (1999a). This resulted in a spike- and trend-corrected time series of $m^{\prime}(t)+\varepsilon(t)$ with zero mean value at each height from 500 to $3000 \mathrm{~m}$ with resolutions of $10 \mathrm{~s}$ and $75 \mathrm{~m}$, respectively. This time series still contains flagged gaps due to small gaps in the data record that occur at all altitudes and due to spikes starting at height levels of $2200 \mathrm{~m}$. The handling of these data gaps is discussed below.

\subsection{Mixing-Ratio Noise Error Profiles}

For each time period for which we wish to determine turbulent variables, noise error profiles have to be derived, as these noise profiles determine whether structures in the derived turbulent profiles are significant. In the following, we assume that system noise is due to statistical errors in the respective backscatter measurements of each channel, and that these errors are uncorrelated both in altitude and in time. Consequently, the spectrum of noise in each channel should be white. There are several techniques available to determine system noise. In a Raman lidar it can be assumed that the noise is Poisson distributed, which can be propagated using an end-to-end model into an error of mixing ratio (e.g., Eq. 6 in Whiteman et al. 2006). Noise profiles can also be determined without application of end-to-end models. Autocovariance analyses of the high-resolution mixing-ratio time series or analyses of mixing-ratio variance spectra are performed for this purpose. These methods are explained in detail in Senff et al. (1994), Wulfmeyer (1999a), and LE2000 so that only the major results are summarized here.

Using the definition

$$
M_{11}(\tau)=\frac{1}{T} \int_{0}^{T}\left(m^{\prime}(t)+\varepsilon(t)\right)\left(m^{\prime}(t+\tau)+\varepsilon(t+\tau)\right) d t
$$

where $\tau$ is time lag and $T$ is the duration of the time series, the system noise variance $\overline{\varepsilon^{2}}$ can be estimated by

$$
\overline{\varepsilon^{2}}=M_{11}(0)-M_{11}(\tau \rightarrow 0) \equiv M_{11}(0)-\overline{\left(m^{\prime}\right)^{2}} .
$$

$M_{11}(\tau \rightarrow 0)$ is a symbol for the extrapolation of $M_{11}$ to lag zero and corresponds to the atmospheric mixing-ratio variance $\overline{\left(m^{\prime}\right)^{2}}$, since the system noise in the mixing-ratio time series can be considered uncorrelated for all lags except lag zero. Obviously, Eq. 3 can be used to determine separately atmospheric and noise variances.

It can be shown (Monin and Yaglom 1971; LE2000) that $M_{11}$ can be approximated by the structure function

$$
M_{11}(\tau) \cong \overline{\left(m^{\prime}\right)^{2}}-C \tau^{2 / 3}
$$

for $\tau \neq 0$ if the atmospheric turbulence is sufficiently resolved. $C$ is a scaling parameter that is related to the turbulent eddy dissipation.

Using Eqs. 3 and 4, the variance and the noise profiles can be derived simultaneously. Determination of system noise using this method is called the autocovariance technique, which is very convenient, since it is based on direct measurements of $m$. Other sources of system noise will be included, if these exist, and which are not taken into account in pure Poisson statistics error propagation. In other words, if noise errors determined using Poisson statistics and the autocovariance technique are comparable, this proves that the system noise of the respective lidar system is Poisson limited. 
There are two common ways for determining $\overline{\varepsilon^{2}}$. A fast and simple technique is setting $\overline{\varepsilon^{2}} \approx M_{11}(\delta t)$ but this approximation disregards the shape of $M_{11}$ close to lag zero, which is generally neither linear nor constant. Consequently, this approximation can lead to an overestimation of system noise. The most accurate approach is the extrapolation of $M_{11}$ to lag zero using Eq. 4. This can be achieved by a linear extrapolation of $M_{11}$ to lag zero or by fitting the structure function to $M_{11}$ (see Eq. 3 in combination with Eq. 4).

In our work, we investigated the covariance functions over the entire height range in order to determine the most appropriate numbers of data points for the extrapolation back to lag zero. Many data points are beneficial for reducing the remaining noise in the regression but if this number is chosen too large, the procedure causes a systematic underestimation of the atmospheric variance (see Eqs. 3 and 4). It turned out that an 11-point extrapolation was the best compromise for the linear extrapolation and the fit of the structure function, which worked both in regions with significant turbulence as well as in regions with spikes and large system noise.

It is important to evaluate the effect of spikes on the separation of atmospheric and noise variances. Consider a time series with spikes that were successfully detected and removed from the time series. Afterwards, trend correction by a spectral filter is necessary. In the resulting time series, the data gaps are filled with zero in order to maintain a zero mean and for calculating autocovariance functions of different orders. It is difficult to estimate the resulting systematic effect, since this spike detection, removal, and gap filling technique will also influence the shape of the autocovariance functions around lag zero. As we are not focusing on a detailed comparison of higher-order moment profiles with turbulence theory or simulations, we just provide an estimation of the systematic error. If it is assumed that the spike values due to the attenuation of the laser beam by clouds are on average of the order of the total variance of the time series, then the difference between the estimated variance and the theoretical variance around lag zero can be approximated by $\left[\sum_{i=1}^{n_{s}} m_{i}^{2}\right] / N \approx \frac{n_{s}}{N} M_{11}$, where $n_{s}$ is the number of spikes and $N$ is the number of data points. Since in our case $n_{s}<100$ up to the entrainment zone and $N=706$, consequently the estimated relative errors at lag zero (total variance of time series) and at lag 1 (atmospheric variance $\overline{\left(m^{\prime}\right)^{2}}$ ) are about $14 \%$. This is of the order of the atmospheric sampling errors.

Figure 8 shows $M_{11}$ at five different heights during our analysis period on September 13, 2005. The difference between the peak at zero lag to the first lag is already a first estimate of the system noise variance. The structure of $M_{11}$ at larger lags indicates whether the SNR is large enough to resolve the structure function. At about $800 \mathrm{~m}\left(0.3 z / z_{i}\right.$, not shown $)$ up to the entrainment zone (for this case, see panel e), the system noise level becomes low enough for resolving the atmospheric variance. In the free troposphere, the SNR is too low to resolve the atmospheric turbulent structure (panel f).

The spectral technique is based on the assumption that the system noise is white. By calculating the variance spectrum of $m$, the spectral value close to the Nyquist frequency $S_{m^{\prime}}\left(v_{n}\right)$ can be estimated, and so

$$
\overline{\varepsilon^{2}} \cong S_{m^{\prime}}\left(v_{n}\right)\left(v_{n}-\frac{1}{T}\right) .
$$

The spectral and the autocovariance techniques are mathematically equivalent and should yield comparable results if the correct extrapolation of the autocovariance function to lag zero is applied. On the one hand, the autocovariance technique has the advantage that system noise can directly be determined without introducing additional errors by Fourier transformation of the autocovariance function. On the other hand, the spectral analysis is an instructive way 

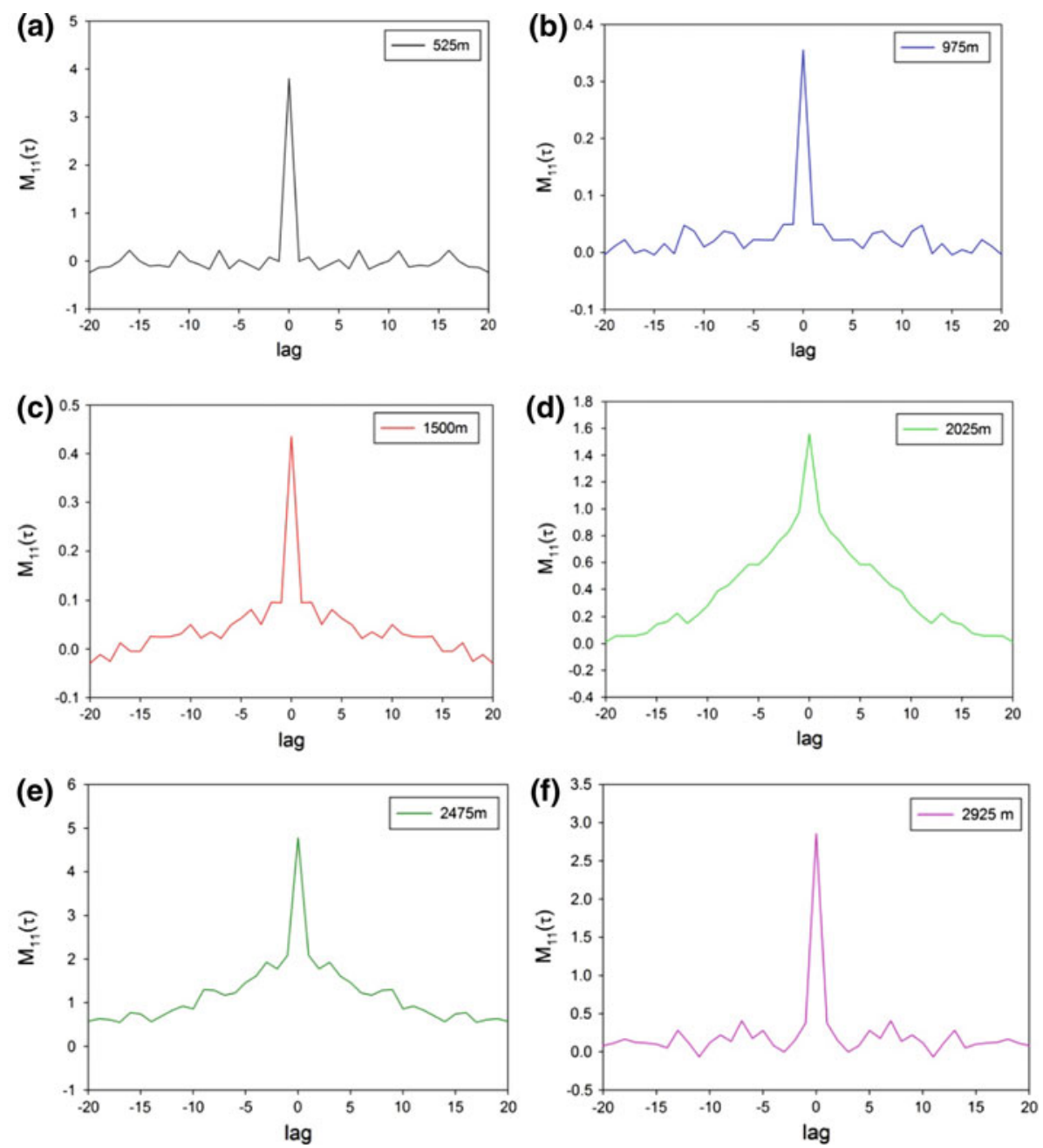

Fig. 8 Autocovariance function $M_{11}$ of mixing ratio presented for five different height levels. a $525 \mathrm{~m}$, b $975 \mathrm{~m}$, c $1500 \mathrm{~m}$, d $2025 \mathrm{~m}$, e $2475 \mathrm{~m}$, f $2925 \mathrm{~m}$. One lag corresponds to a shift of $10 \mathrm{~s}$ of the time series in the autocovariance function

to observe whether the major part of the turbulent fluctuations is resolved by comparing the high-frequency part of the spectrum with the theoretical decay in the inertial subrange.

Figure 9 presents variance spectra of $m$ during the same observation periods and at the same heights as in Fig. 8. The straight line shows the theoretical decrease of the respective spectra according to the $-5 / 3$ power law in the inertial sub-range (Kolmogorov 1941). It is clear from Fig. 9 that, from the lower CBL up to the entrainment zone, the system resolves the atmospheric variance including the inertial subrange. This is consistent with the discussion of Fig. 8.

Figure 10 compares the noise error profiles derived using Poisson statistics as well as the autocovariance and spectral methods. The root-mean-square (rms) error of the determination of the noise error by linear extrapolation to lag zero is also shown. It is very satisfying to see that Poisson statistics determines the lower bound of system noise. All noise variance profiles 


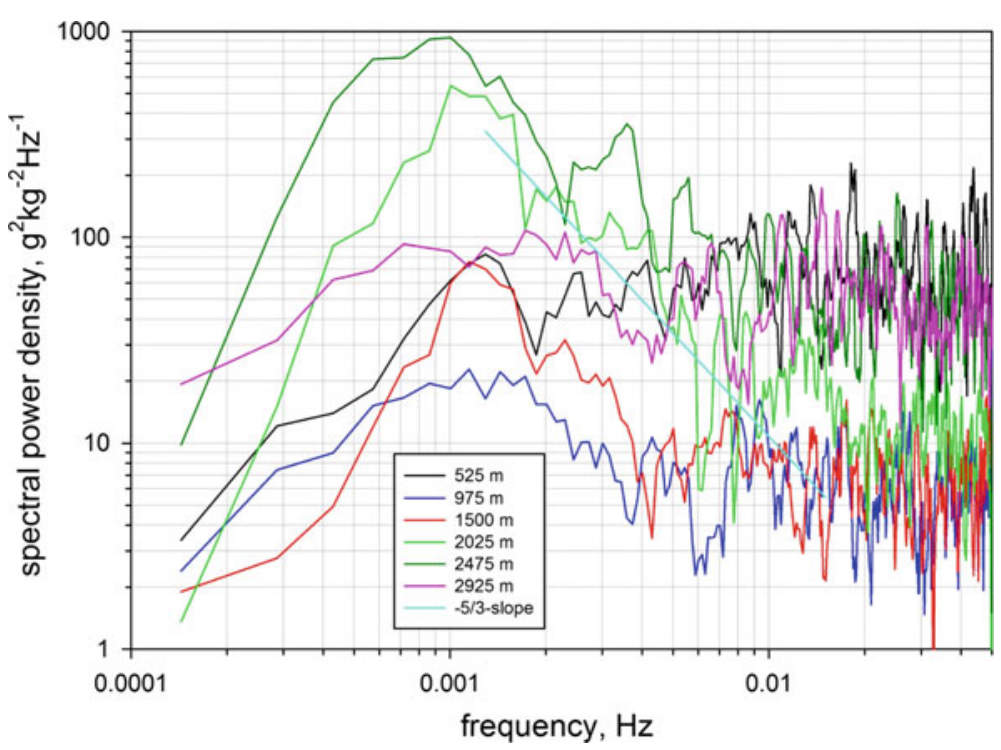

Fig. 9 Power spectra of mixing ratio in double logarithmic scales presented for six different height levels, as in Fig. 8. The straight line indicates the theoretical decay of spectral power in the inertial subrange

agree well quantitatively with the estimation of system noise variance using Poisson statistics starting at heights above $1000 \mathrm{~m}$. This analysis shows that, below $1000 \mathrm{~m}$, the noise variance exceeds Poisson statistics due to enhanced fluctuations in the determination of mixing ratio by the overlap function. Otherwise, the other noise profiles deviate from Poisson statistics mainly in the region of clouds. This is reasonable, since the variance in the mixing ratio increases due to a higher variability of the Raman signals.

The noise variance profiles agree very well between the extrapolation of the autocovariance function and the spectral method. As expected, the approximation of the noise variance using the difference between lag zero and lag 1 of the autocovariance function results in a slight overestimation of system noise (varnoi_lag in Fig. 10). The fit of the structure function to $M_{11}$ (varnoi_pow in Fig. 10) is considered most accurate, as this procedure considers as best as possible the physical shape of the autocovariance function around lag zero. If the noise levels are very high, it may be preferable to use a linear extrapolation to lag zero; however, in our analysis, the fit of the structure function turned out to be very robust over the entire range. Furthermore, the structure function fit showed the most reasonable behaviour in the entrainment zone and resulted in a small reduction in magnitude of the noise variance profiles, since more variance was attributed to atmospheric fluctuations. In the following, the noise variance profile derived with the structure function (i.e., varnoi_pow) is used in all further error propagation analyses.

The square root of varnoi_pow can be considered as a good estimate of the standard deviation of a CARL mixing-ratio measurement using resolutions of $10 \mathrm{~s}$ and $75 \mathrm{~m}$. Therefore, we define this profile as the absolute rms error. The relative error of mixing-ratio measurements can be estimated by dividing the rms error profile by the mean profile of mixing ratio during the measurement period. This procedure is reasonable, as long as no strong variability in the mixing-ratio field occurs, which was the case during the time period analyzed here. 


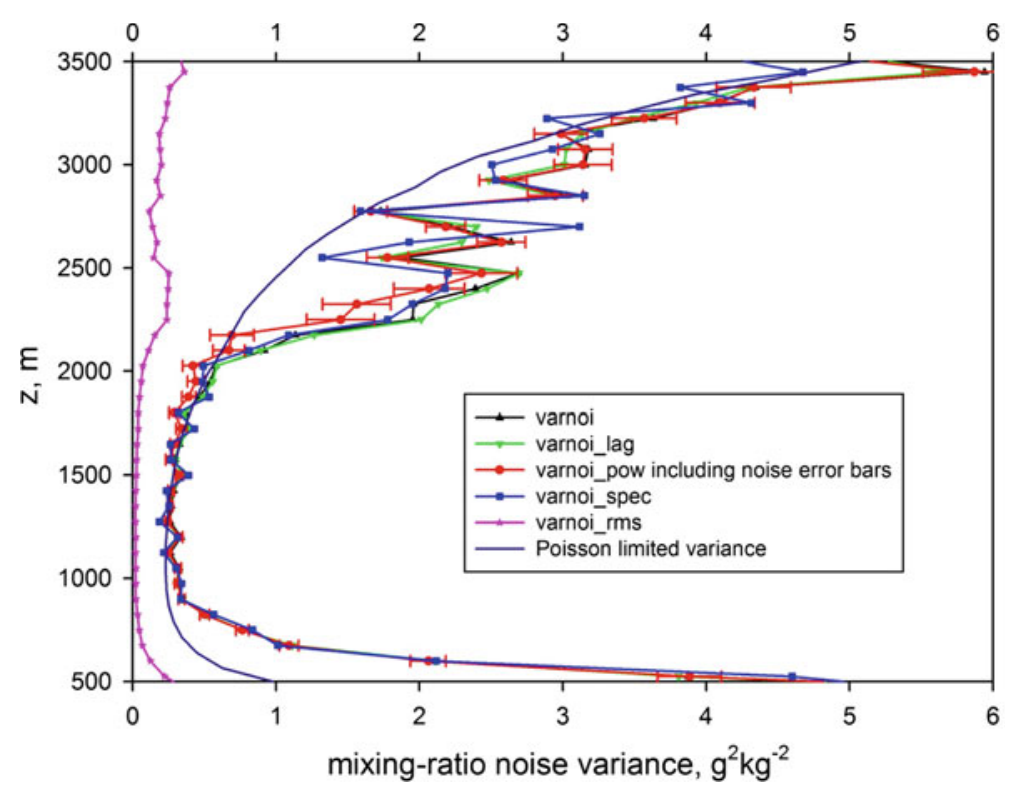

Fig. 10 Comparison of CARL noise variance estimation of the narrow FOV water vapour mixing ratio data using four different techniques. Varnoi: 11-point linear extrapolation to lag zero (this line is largely covered by the other variance estimates, as it was the first line plotted), varnoi_lag: difference between lag zero and lag 1 of $M_{11}$, varnoi_pow: extrapolation of structure function to lag zero, varnoi_spec: high-frequency section of variance spectrum, and Poisson-limited variance: the theoretical lower limit of system noise given by photon statistics. The error of the noise variance profiles (varnoi_rms), determined by the regression analyses statistics, is also shown, which is plotted as error bars in varnoi_pow

Both profiles (rms error and relative error) are presented in Fig. 11 including the corresponding profiles derived by Poisson statistics. Again, it is seen that Poisson statistics are not sufficient to explain the system noise up to $800 \mathrm{~m}$. Here additional variance caused by overlap effects increases the rms error considerably. The results demonstrate that CARL is capable of measurements with an absolute error of $<2 \mathrm{~g} \mathrm{~kg}^{-1}$ and a relative error of $<30 \%$ up to $3 \mathrm{~km}$ using resolutions of $10 \mathrm{~s}$ and $75 \mathrm{~m}$, respectively. As the relative error with respect to system noise of the determination of turbulent moments is nearly proportional to the square root of the ratio of the noise and atmospheric variances (Wulfmeyer 1999a,b, and LE2000), Fig. 11 indicates that it should be possible to derive atmospheric variance profiles above $800 \mathrm{~m}$ up to the entrainment zone.

\subsection{Systematic Error Profiles}

Systematic errors in the lidar water vapour mixing-ratio profiles can be due to the lidar system, such as a time dependent bias in the calibration, overlap effects, and other systematic error sources in the receiver. It was shown above that these effects can be neglected.

However, atmospheric effects can also cause systematic errors in the determination of turbulence profiles even if the CARL measurements are perfect. There are two major systematic error sources: (A) sampling errors due to insufficient sampling of the ensemble of turbulent fluctuations around the measurement site, (B) filtering of the turbulent time series due to limited temporal and spatial resolutions. 


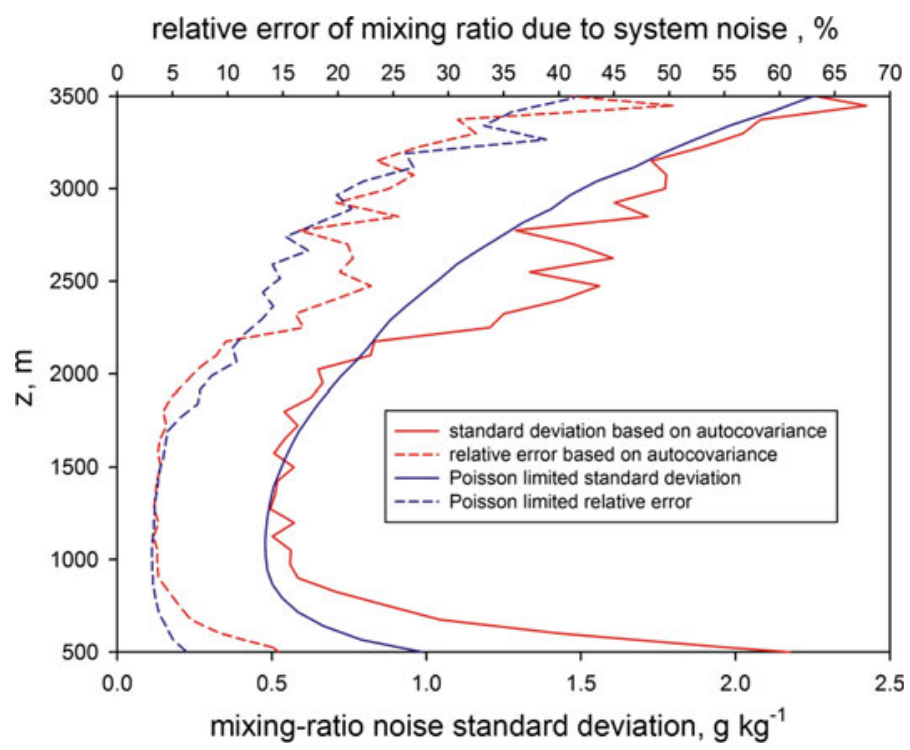

Fig. 11 Corresponding absolute and relative error profiles of CARL mixing-ratio measurements using the square root of varnoi_pow in Fig. 10

These effects can be studied by estimating the integral time scale $\Pi$ of the moment of $m$ to be considered. For instance, for the mixing-ratio variance (LE2000)

$$
\Pi=\frac{1}{\overline{\left(m^{\prime}\right)^{2}}} \int_{\tau \rightarrow 0}^{\infty} M_{11}(\tau) d \tau,
$$

where the integral time scale can be considered as a measure of the typical size of a turbulent eddy in the temporal domain. If the Taylor hypothesis (frozen turbulence) is appropriate, the spatial scale $R$ of this eddy can be estimated by $R \approx U \Pi$ where $U$ is the horizontal wind speed.

(Source A) Due to its physical meaning, atmospheric sampling error profiles for all higherorder moments and their combinations can be calculated after estimating the profiles of $\Pi$ by application of turbulence statistics based on the theory derived in Lenschow and Kristensen (1985); Lenschow and Stankov (1986); Lenschow et al. (1994), and Mann et al. (1995).

(Source B) Before higher-order moments of $m$ are calculated, it is important to investigate whether the major part of the turbulent fluctuations was resolved by the remote sensing system. Since CARL is not a point sensor, the measurement process can be considered as temporal-spatial filter functions to the time series of $m$. This distorts the turbulence spectrum and the autocovariance function when these are compared to results achieved with a point sensor.

A prerequisite for the resolution of the major part of the turbulent fluctuations is $\Pi \gg \delta t$ where $\delta t$ is the temporal resolution of the time series $(10 \mathrm{~s}$ in our analysis here). If this condition is achieved, the major part of the turbulent eddies is sampled with acceptable resolution so that the inertial subrange in the spectrum and/or the dissipation range in 


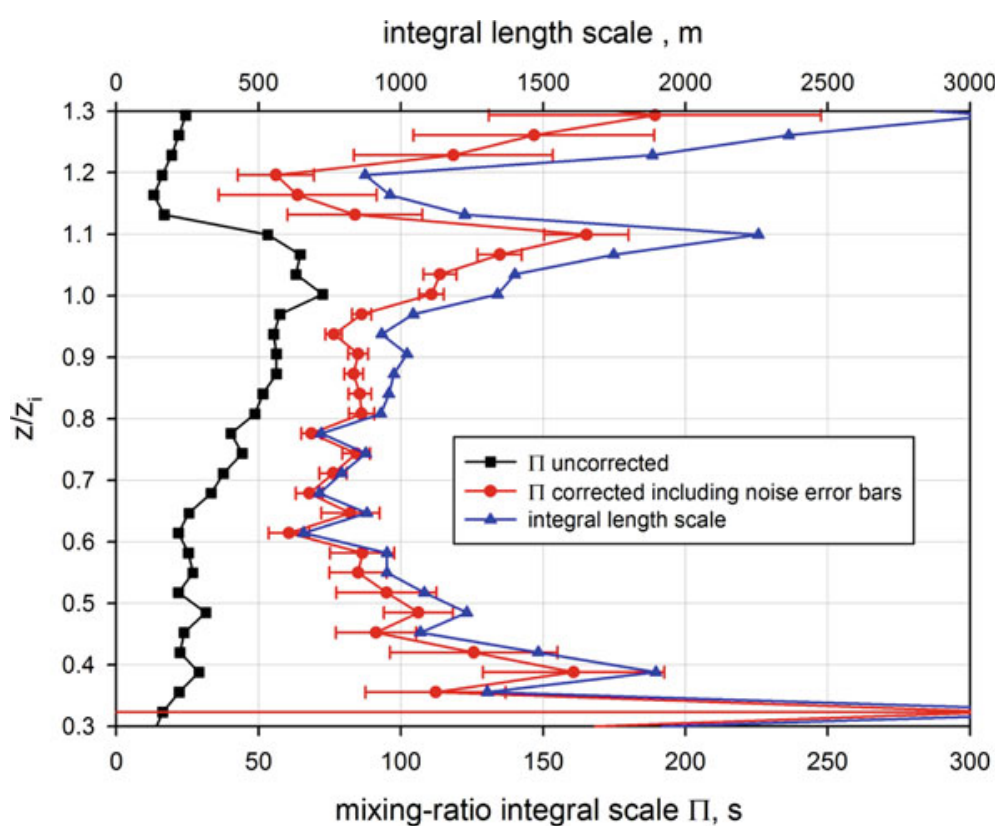

Fig. 12 Estimation of the integral scale of $m$ with and without correction of the atmospheric variance profile with respect to system noise. In the corrected profile, the noise error bars are also shown. The integral length scale, computed assuming the frozen turbulence hypothesis and radiosonde data at 2330 UTC (i.e., after the period of Raman lidar data analyzed here), is also shown

the autocorrelation function of the mixing ratio becomes resolved. This does not necessarily imply that the inertial subrange is visible in the variance spectrum. It may still be the case that the atmospheric variance is masked by a large noise variance (see Fig. 9).

Figure 12 presents the profile of $\Pi$ during the observational period. The vertical coordinate is the normalized boundary-layer depth, i.e., $z$ divided by the mean CBL depth $\bar{z}_{i, A S R}$. Experimental data and LES indicate that the maximum of the atmospheric variance profile should be close to $1.0 \mathrm{z} / z_{i}$. However, there is uncertainty associated with the actual boundary-layer top height determination that has to be addressed if detailed comparisons with similarity relationships or LES are performed in future analyses.

Equation 6 shows that the atmospheric variance is captured in the denominator of the calculation of $\Pi$. The black line in Fig. 12 is the profile of the integral scale when correction for system noise in the variance profile is not performed, whereas the red line shows the integral scale after this correction is applied (see Eqs. 3, 4, and 6). Obviously, this correction is important and essential over the entire boundary layer. Furthermore, assuming Taylor's hypothesis of frozen turbulence is valid, we added the profile of the integral length scale (blue line), which is the product $\Pi U(z)$ where $U(z)$ is the horizontal wind profile from the 2330 UTC radiosonde profile. Both profiles $\Pi U(z)$ and $U(z)$ were very similar in shape, as the horizontal wind profile did not change substantially with height in the height range plotted in Fig. 12.

The inspection of the vertical structure of $\Pi$ presented in Fig. 12 including the error bars indicated a decrease of $\Pi$ from 150 to $80 \mathrm{~s}$ (1800 to $800 \mathrm{~m}$ for $\Pi U$ ). From 0.9 to $1.1 z / z_{i}$, $\Pi$ increased from 80 to $160 \mathrm{~s}$ ( 800 to $1600 \mathrm{~m}$ for $\Pi U$ ). Though the values up to $0.7 z / z_{i}$ and 
above $1.1 z / z_{i}$ are prone to significant errors, the condition $\Pi>>\delta t$ over the entire range of interest from 0.3 to $1.1 z / z_{i}$ suggests that CARL sampled the major part of the turbulent fluctuations in the CBL.

A more detailed estimation of unresolved turbulence by temporal and spatial averaging can be achieved by application of reasonable models of turbulence in combination with the study of the effect of the filter function (for details see LE2000 and Frehlich 1997). One critical scaling parameter is the ratio between the vertical resolution $\delta R$ of the lidar system and the horizontal length scale $L=U \Pi$ where $U$ is horizontal wind speed. In our case, $\delta R=75 \mathrm{~m}, U \approx 10 \mathrm{~m} \mathrm{~s}^{-1}, \Pi=80 \mathrm{~s}$ hence $L=800 \mathrm{~m}$ so that $\delta R / L \approx 0.1$. This results in a reduction of variance of the order of $10 \%$, which is acceptable (Frehlich 1997). The other scaling parameter is the ratio between the horizontal resolution $\delta t \cdot U$ and $L$, which yields $\delta t \cdot U / L=\delta t / \Pi \approx 0.12$. In this case, it can be shown that the deformation of the variance spectra and the structure functions is weak. This is also seen by comparing the fits of the $-5 / 3$ slope to the log-log representation of the variance spectra in Fig. 9 and the shape of the structure functions in Fig. 8, in the region where the system noise was sufficiently small. Consequently, in a well-developed, deep CBL, the temporal and spatial resolutions of CARL are able to resolve the major part of the turbulent fluctuations of $m$.

\subsection{Higher-Order Moments of Mixing Ratio and System Noise}

Higher-order moments up to the fourth order, as well as the mixing-ratio skewness and kurtosis, were determined. The methodology and the noise error propagation were applied to the equations of the higher-order moments of $m$ based on the work introduced in LE2000. For instance, the noise error $\Delta \overline{\left(m^{\prime}\right)^{2}}$ of the variance profile reads:

$$
\Delta \overline{\left(m^{\prime}\right)^{2}} \cong \overline{\left(m^{\prime}\right)^{2}} \sqrt{\frac{4}{N} \frac{\overline{\varepsilon^{2}}}{\overline{\left(m^{\prime}\right)^{2}}}}
$$

where $N$ is the number of data points during the observational period. Equation 7 demonstrates the importance of low noise errors for an accurate determination of variance profiles. It also illustrates that the relative noise error of the atmospheric variance is proportional to the square root of the ratio of instrumental noise and atmospheric variance. Further equations for the determination of noise errors of the integral scale $\Pi$, the skewness $S$, and the kurtosis $K$ of $m$ can be found in LE2000. In all figures presented in this work, corresponding noise errors were derived and included in the results.

Figure 13 presents the first total and atmospheric variance profiles corrected for system noise in a convective boundary layer up to the top of the entrainment zone determined with a Raman lidar. The noise correction appears to work very well even down to $0.3 z / z_{i}$ and in the entrainment zone. Also noise and sampling error profiles are shown, which indicate how well the structure of the profile can be determined. Figure 13 demonstrates that both errors are sufficiently low for a detailed scientific analysis of the atmospheric variance profile. From 0.3 to $0.6 z / z_{i}$, the variance profile is nearly constant with a value of about $0.1 \mathrm{~g}^{2} \mathrm{~kg}^{-2}$, then, the variance increased nonlinearly up to a maximum of $3.7 \mathrm{~g}^{2} \mathrm{~kg}^{-2}$ around $0.95 z / z_{i}$. Here, in the entrainment zone, the variance must reach a maximum, since the variability due to the vertical exchange by strong updrafts and downdrafts has the largest impact. The variance decreases strongly above $z_{i}$ and reaches about $0.2 \mathrm{~g}^{2} \mathrm{~kg}^{-2}$ at $1.15 z / z_{i}$. The full width at half maximum (FWHM) is about $0.16 z / z_{i}$. Potential applications of these results are discussed in Sect. 6. 


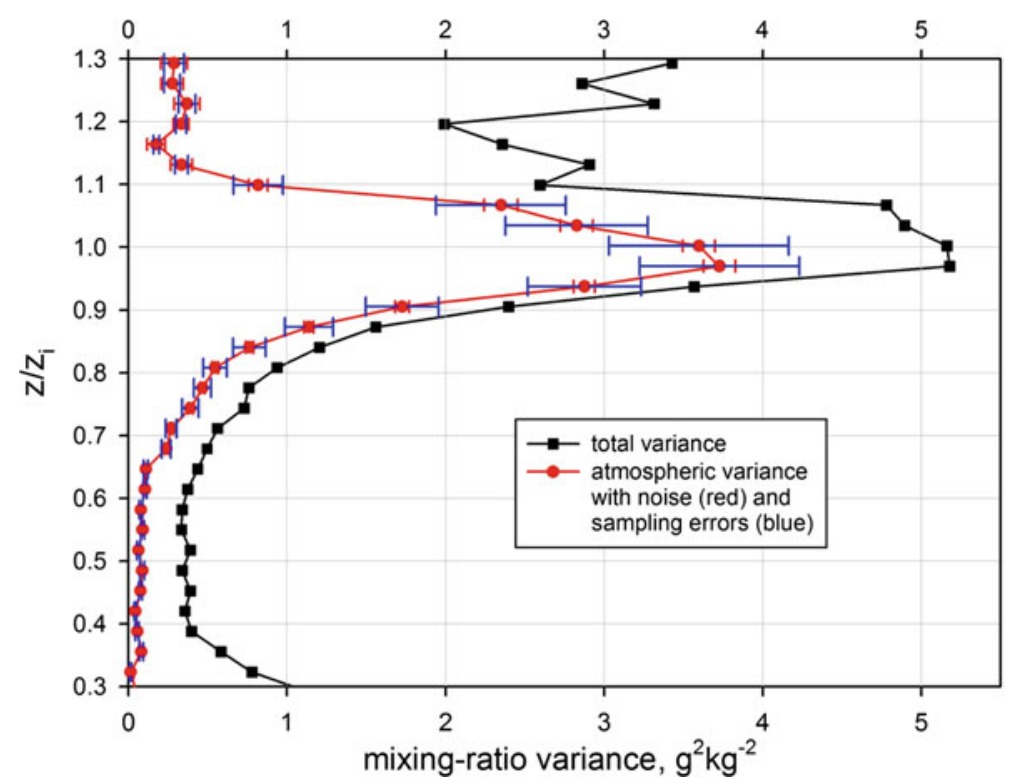

Fig. 13 Vertical distribution of the mixing-ratio variance uncorrected and corrected for system noise. It is obvious that noise correction is essential. In the corrected profile, also the noise and sampling error bars are shown

Figure 14 shows the skewness profile for the same dataset as described above without correction for system noise (total skewness), and with noise correction (atmospheric skewness) using the eleven-point linear extrapolation to zero lag of the third-order moment normalized by the noise corrected atmospheric variance profiles shown in Fig. 13. Noise and sampling errors are also shown in the corrected profile. The noise errors are large from the surface up to $0.5 z / z_{i}$ and above $1.1 z / z_{i}$ making the interpretation of the skewness data difficult in these regions. The skewness is nearly zero up to $0.6 z / z_{i}$, and in the centre of the CBL up to $0.9 z / z_{i}$, it becomes negative and reaches values of about -1 . From 0.9 to $1.15 z / z_{i}$, the skewness increases linearly with height, crossing zero at about $0.95 z / z_{i}$, and achieves a maximum value of approximately 3 just above the top of the CBL (at $1.16 z / z_{i}$ ).

Figure 15 presents the kurtosis profile. If the mixing-ratio fluctuations are Gaussian distributed, the kurtosis is 3. To detect deviations from the Gaussian distribution requires an accuracy of kurtosis measurements of significantly less than 1 , which is not the case here as the system noise levels result in error bars on the derived kurtosis profile that are much larger. Therefore, we conclude that the noise level in the Raman lidar observations is not small enough to meaningfully derive kurtosis profiles.

Finally, we study CARL noise errors and its higher-order moments. In LE2000, equations for $\overline{\varepsilon^{3}}, \overline{\varepsilon^{4}}, \overline{\left(m^{\prime}\right)^{2} \varepsilon^{2}}$ were derived. Particularly, if signal and atmospheric variances are uncorrelated, the condition

$$
\operatorname{cor} r=\frac{\overline{\left(m^{\prime}\right)^{2} \varepsilon^{2}}}{\overline{\left(m^{\prime}\right)^{2}} \overline{\varepsilon^{2}}} \cong 1
$$

should be fulfilled. Figure 16 presents the first attempt to apply this technique to the CARL data showing the correlation function corr both uncorrected and corrected for system noise based on Eq. 8. Unfortunately, the noise error bars of products of second-order moments are 


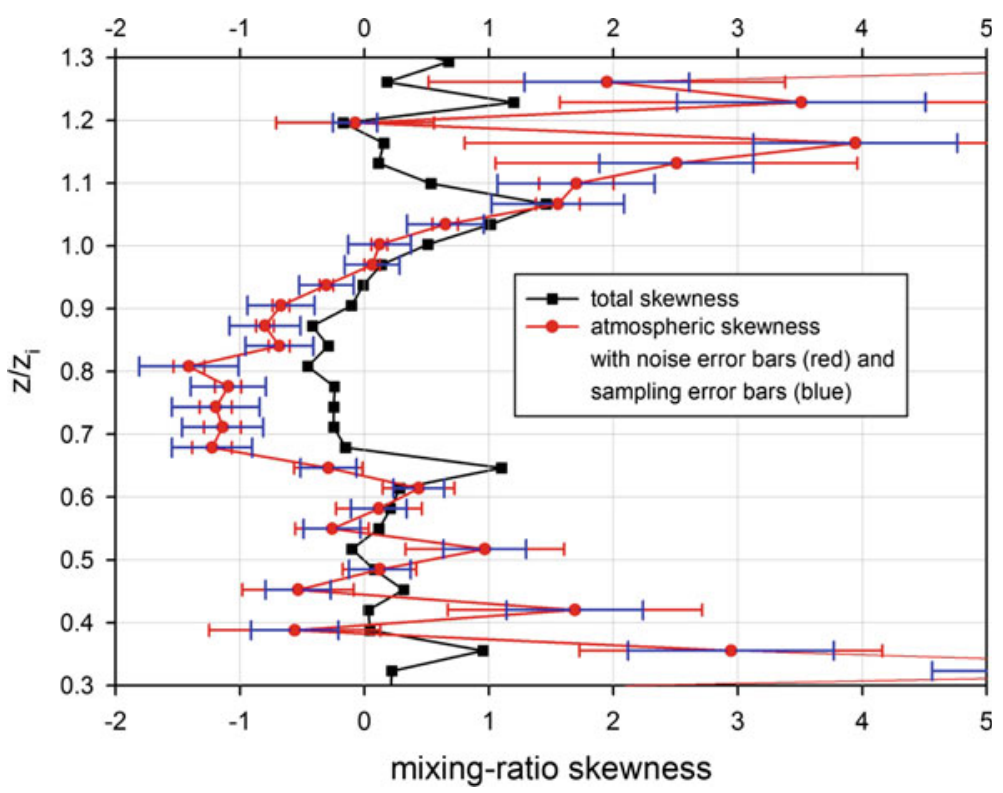

Fig. 14 Water vapour mixing ratio skewness profile without and with noise correction with two different methods. Statistical and sampling errors are also shown

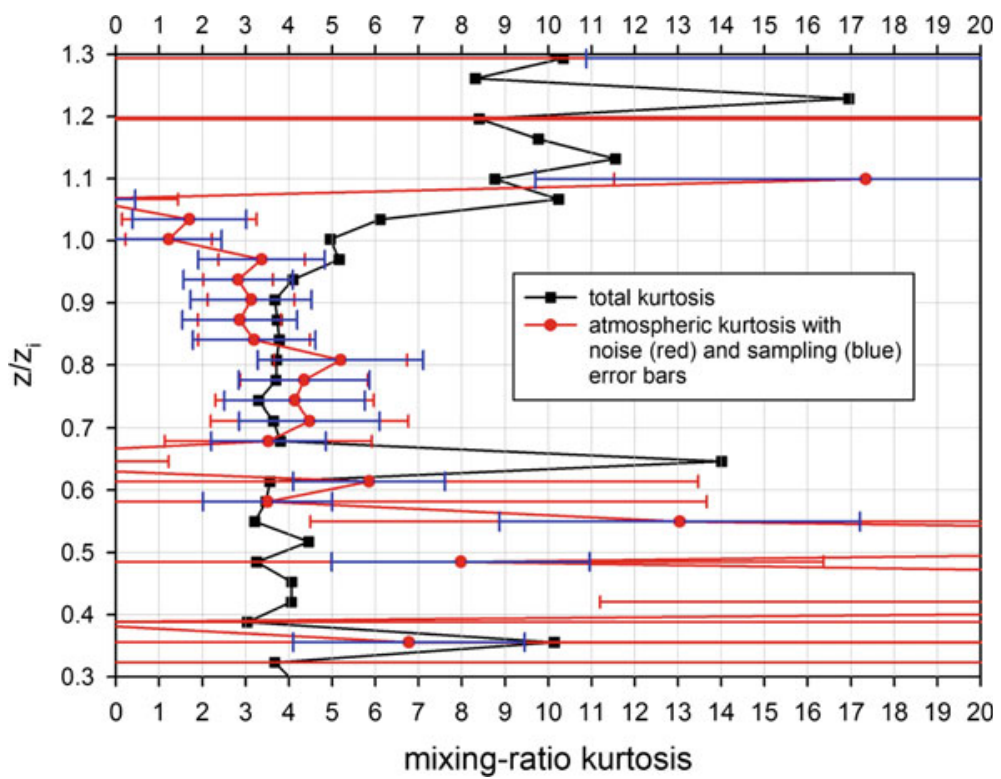

Fig. 15 Vertical profile of kurtosis with and without correction. The sampling and noise errors are also shown

large so that details in the correlation of system noise and atmospheric variance cannot be detected. Nevertheless, within the range of noise errors, no systematic deviation was found, so that no correlation of system noise and atmospheric variance was observed in the range 0.5 to $1.0 z / z_{i}$. 


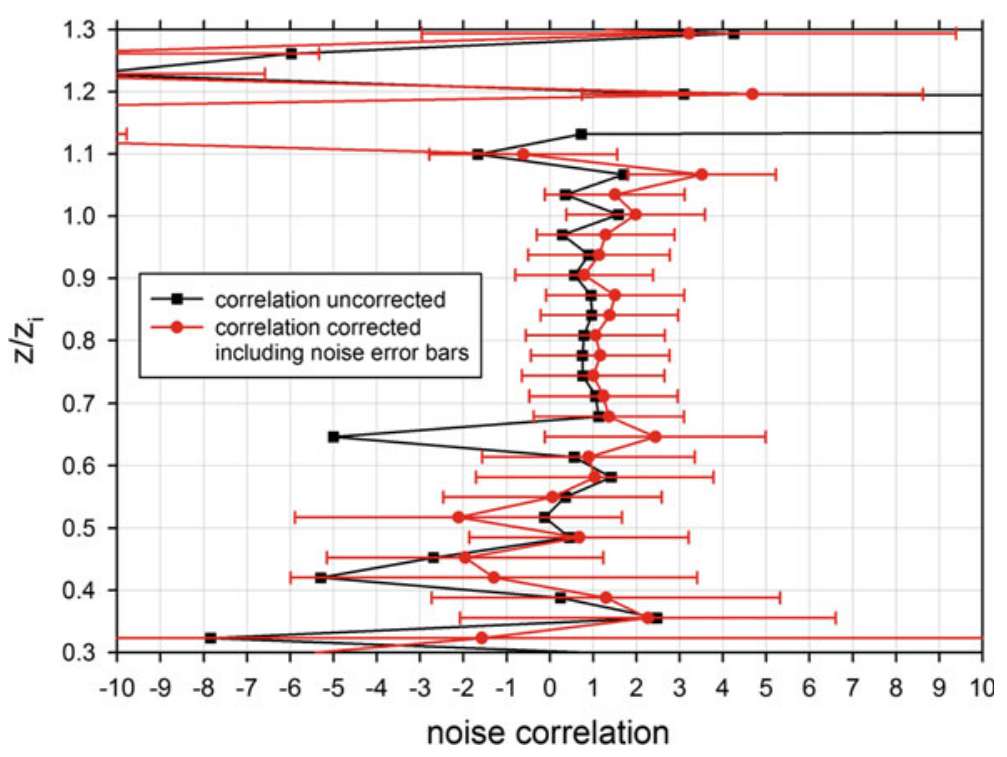

Fig. 16 Vertical profile of correlation test function with and without a noise correction. The noise errors are also shown

\section{Discussion}

In the following, we compare our results concerning the integral scale, the variance, and the skewness profiles with other measurements and LES. We disregard effects due to a possible negative bias in $\overline{z_{i}}$, since we are not performing a detailed comparison of turbulence profiles with similarity relationships or LES. However, this uncertainty will need to be addressed if more detailed comparisons are performed.

Other turbulence measurements were performed using in-situ sensors or DIAL, the latter being the only water vapour remote sensing technique to date that is able to meet the stringent requirements with respect to resolution and SNR. With LES, the complex threedimensional exchange and transport processes in the convective or shear-driven atmospheric boundary layer in clear or cloudy skies can be modelled (e.g., Couvreux et al. 2005, 2007) and scaling laws derived (e.g., Moeng and Wyngaard 1984; Sorbjan 1996, 2001, 2005). In our observations in relatively flat and homogeneous terrain, the turbulence was mainly driven by buoyancy so we focused on LES results in similar environments.

We measured a minimum of the dimensionless ratio of $\Pi U / z_{i} \approx 0.34$ in the centre of the CBL (0.6-0.8 $z / z_{i}$ ), which increased towards the surface and the CBL top (see Fig. 12). Only a few other measurements of the profiles of $\Pi$ are available. Based on aircraft in-situ measurements, Lenschow and Stankov (1986) claimed that $\Pi U / z_{i} \propto\left(z / z_{i}\right)^{0.5}$; however, this could not be verified in our case due to the decrease of $\Pi$ in the centre of the CBL. Kiemle et al. (1997) studied several aircraft measurements over boreal forest and found $\Pi U / z_{i} \approx 1.25$. In the CBL over land, Kiemle et al. (2007) observed $\Pi U / z_{i} \approx 0.4-1.1$. In both studies, they found indications for a slight decrease of $\Pi$ from $0.4 z / z_{i}$ up to the CBL top. In a marine CBL, Wulfmeyer (1999a,b) determined $\Pi U / z_{i} \approx 0.7$, and studying the dataset of Wulfmeyer (1999a) in more detail, LE2000 observed an average value of $\Pi U / z_{i} \approx 0.8$ and, as with Kiemle et al. $(1997,2007)$, a slight decrease of $\Pi$ towards the CBL top. Previous 
measurements did not show an increase of $\Pi$ towards the CBL top but confirmed the slight reduction of $\Pi$ from the lower CBL to the centre of the CBL. The non-linear structure of the $\Pi$ profiles makes the application of simple scaling laws (polynomial and/or a power-law dependence of $z / z_{i}$ ) difficult.

$\Pi$ profiles derived from LES data have only been provided in a few publications. Recently, Couvreux et al. (2005) presented detailed large-eddy simulations of the CBL during IHOP_2002 (Weckwerth et al. 2004). The qualitative agreement with our profile is striking. They found a similar shape of the profile and explained the shape of this profile through the existence of dry tongues of air that entrain downwards in the CBL from the free troposphere. The presence of these tongues results in different turbulence statistics in comparison to vertical velocity, and causes a decrease of $\Pi$ in the CBL. A larger $\Pi$ around $z_{i}$ can occur if the skewness of mixing ratio in this region becomes about zero, as the shape of updrafts and downdrafts becomes more symmetric. Obviously, $\Pi$ and the mixing-ratio skewness are related to each other (compare Figs. 12, 14).

The higher-order moments of water vapour (i.e., the variance and skewness) profiles provide insight into the turbulent structure of, and transport within, the CBL. Recently, both Wulfmeyer (1999b) and Couvreux et al. $(2005,2007)$ investigated the skewness of the water vapour profile in the CBL using both high-resolution lidar observations and LES model simulations. Couvreux et al. (2005) demonstrated that the negative skewness in the CBL is due to the entrainment of dry air pockets ('dry tongues') into the boundary layer. These dry tongues gradually mix with the environmental air and mix out somewhere near the middle of the boundary layer (Couvreux et al. 2007). This appears to be a possible explanation for the negative skewness observed in the upper portion of the CBL in our case study (Fig. 14). The positive skewness values above the top of the CBL are likely associated with the centre of the convective plumes that penetrate to this height; in these "cores" the humidity also reaches saturation and clouds form. However, Couvreux et al. (2007) also suggest that the sign of the skewness at the top of the boundary layer has a dependence on the humidity gradient above the CBL. The near-zero skewness values in the lowest portion of the CBL below $z / z_{i}<0.6$ in our case are probably due to the lack of a significant moisture flux from the surface (see Fig. 2), as argued by Mahrt (1991).

Lidar studies (e.g., Kiemle et al. 1997, 2007; Wulfmeyer 1999a,b; LE2000) have confirmed that the water vapour variance increases with height, achieving a maximum at the top of the CBL due to the mixing of moist air in the updrafts with the drier air from above the CBL. The general shape of our water vapour variance profile (Fig. 13) agrees well with these previous measurements. Furthermore, our variance profile has a higher vertical resolution, in contrast to airborne remote sensing measurements, which makes it easier to compare the results with similarity relationships or LES.

In our case, the magnitude of the variance at the top of the CBL is about $3.7 \mathrm{~g}^{2} \mathrm{~kg}^{-2}$ with a FWHM of $\approx 0.16 z / z_{i}$. The maximum variance values in Wulfmeyer (1999a,b) and LE2000 were much smaller $\left(\approx 0.1-0.2 \mathrm{~g}^{2} \mathrm{~kg}^{-2}\right)$ and the FWHM values were larger $\left(\approx 0.3-0.5 z / z_{i}\right)$. Kiemle et al. (1997) found a maximum variance of $0.3-0.45 \mathrm{~g}^{2} \mathrm{~kg}^{-2}$ with an FWHM of $0.25-0.3 z / z_{i}$ over a boreal forest and Kiemle et al. (2007) found a maximum variance of $0.7 \mathrm{~g}^{2} \mathrm{~kg}^{-2}$ in the CBL over land (FWHM not defined), respectively.

These results lead to the following question: what parameters or processes govern the shape and the maximum value of the mixing-ratio variance profile? It is clear that surface forcing should mainly determine the variance profile in the lower CBL. During our measurement period, we derived the following values for the scaling variables: the convective velocity scale, $w_{*} \approx 2 \mathrm{~m} \mathrm{~s}^{-1}$, the convective humidity scale $m_{*} \approx 0.01 \mathrm{~g} \mathrm{~kg}^{-1}$, and convective time scale $t_{*} \approx 1160 \mathrm{~s}$, which may be used for studying the variance profile in the lower CBL 
height range. The major information content of the variance profile is given by its shape and strength in the entrainment zone, and the vertical range and resolution of CARL allows us to focus on this region. The main factors driving turbulence around $z_{i}$ are mainly the strength of the inversion (Sorbjan 1996) and the moisture gradient (Sorbjan 2005). Wulfmeyer (1999b) pointed out that under realistic conditions, it can also be expected that the entrainment rate and entrainment flux are dependent on the wind shear and on the presence of gravity waves. Furthermore, our observations contained fair weather cumulus clouds, and future work will investigate the dependence on the magnitude of the water vapour variance on the presence of cumulus clouds.

LES allows a deeper insight into entrainment processes, and simulations have shown that entrainment in the CBL is often driven by top-down and bottom-up diffusion processes, with a decaying influence of the bottom-up diffusion process with height in the CBL (Wyngaard and Brost 1984). Moeng and Wyngaard (1984) applied this concept and proposed that the variance profile of a scalar can be constructed by the sum of three dimensionless functions for bottom-up, top-down, and bottom-up-top-down correlations for scaling parameters, the ratios between the surface and entrainment fluxes and $w_{*}$ were chosen.

As in Wulfmeyer (1999b) we attempted to fit our variance profile to their top-down bottom-up variance relationship up to $0.9 z / z_{i}$. Whereas the shape of the profile fits our result reasonably well (not shown) we achieved an entrainment flux of $\approx 1000 \mathrm{~W} \mathrm{~m}^{-2}$, which obviously does not make sense. Consequently, as in Wulfmeyer (1999b), we conclude that the relationship derived in Moeng and Wyngaard (1984) is not generally applicable. As scalar fluxes at the top of the entrainment zone are dependent on the temperature and humidity gradients, they cannot be applied as independent scaling parameters. Thus, the set of scaling variables suggested by Moeng and Wyngaard (1984) is not appropriate in the entrainment zone. We made attempts to fit the shape of our variance profile with symmetric distribution functions and found the best agreement with a Lorentzian profile, whereas a Gaussian profile was too steep in the wings of the profile. Further improvements could be achieved by allowing a slight skewness with respect to the vertical distribution.

A very similar shape of a variance profile produced by LES was shown in Couvreux et al. (2005), and this motivated us to study the dependence of the variance profile on similarity parameters in more detail. A promising approach was proposed by Sorbjan (1996, 2001, 2005) based on LES in the CBL. He derived scaling laws that relate the mixing-ratio variance and the moisture-flux profiles to the temperature gradient in the inversion layer (or the Brunt-Vaisala frequency $N$ ), the moisture gradient $g=d m / d z$, and a mixing length scale that is dependent on the vertical velocity variance $\overline{w^{\prime 2}}$ and $N$. This scaling based on gradient functions is called type II similarity. If we assume that turbulence in our case was mainly driven by convection, and that other effects due to wind shear, gravity waves, advection, subsidence, and cloud effects can be neglected, Sorbjan's scaling laws should be applicable. If this free-convection scaling is appropriate, the following relationships can be derived:

(1) If vertical wind and humidity fluctuations are measured simultaneously, then the entrainment flux $F_{E}$ can be estimated by

$$
F_{E} \cong \frac{C_{F}}{\sqrt{C_{m}}}\left(\overline{w^{\prime 2}}\right)_{E}^{0.5}\left(\overline{m^{\prime 2}}\right)_{E}^{0.5},
$$

where the index $E$ indicates that the turbulence profiles have to be evaluated at $z \approx z_{i}$ in the entrainment zone. Two dimensionless parameters appear in this relationship, which we take to be constants. $C_{F}$ is the ratio between the water vapour entrainment flux and the product of the square root of vertical velocity scale and an entrainment 
humidity scale. The humidity variance is assumed to be proportional to the square of the entrainment humidity scale with a constant of proportionality $C_{M}$ (Sorbjan 2001). Obviously, $C_{F} /\left(C_{M}\right)^{0.5}$ is the correlation coefficient of vertical velocity and humidity fluctuations in the entrainment zone. Sorbjan (2001) also provided first estimates of $C_{F}$ and $C_{m}$. However, these estimates still need to be refined by LES with higher resolution (Z. Sorbjan, pers. comm., 2010). In order to apply Eq. 9 for determining the entrainment flux, the vertical velocity variance profile must also be determined or a relationship between $w_{*}$ and $\overline{w^{\prime 2}}$ in the entrainment zone must be derived. Equation 9 can directly be studied if collocated high-resolution Doppler lidar and water vapour lidar (DIAL or Raman lidar) measurements are performed because this instrument combination would also provide a direct estimate of $F_{E}$ using eddy correlation.

(2) If the Brunt-Vaisala frequency, $N$, the moisture gradient, and the moisture variance are available

$$
F_{E} \cong-\frac{C_{F}}{C_{m}}\left(\overline{m^{\prime 2}}\right)_{E} \frac{N_{E}}{\left(\frac{d m}{d z}\right)_{E}}=-\frac{C_{F}}{C_{m}}\left(\overline{m^{\prime 2}}\right)_{E} \frac{N_{E}}{g_{E}} .
$$

Again, this equation needs to be evaluated in the entrainment zone. In our study, the Brunt-Vaisala frequency was not measured so we keep this exciting possibility to determine the entrainment flux for future research. Remotely sensed measurements of the Brunt-Vaisala frequency are now possible with water vapour DIAL (Behrendt et al. 2009) or Raman lidar in combination with temperature rotational Raman lidar (Radlach et al. 2008).

(3) Moistening and drying of the CBL can be determined if a relationship between the vertical velocity variance and $w_{*}$ is derived (Sorbjan 2005). In this case, the ratio between $F_{E}$ and the surface flux $F_{0}$ reads

$$
V \equiv \frac{F_{E}}{F_{0}}=C \frac{\sqrt{\overline{m^{\prime 2}}} E}{m_{*}} .
$$

If $V>1$, the CBL is drying, if $V<1$, the CBL is moistening. The constant $C$ is related to the constants in the scaling relationships and can be evaluated with LES. In Sorbjan (2005) a first estimation of $C$ was given: $C \approx 0.054$. In our case, we find $V \approx 10$ at $z_{i}$ so that drying of the CBL was expected. This is consistent with the results presented in Figs. 2 and 6.

\section{Summary and Conclusions}

In September 2004, the ARM Raman lidar CARL was refurbished and upgraded, thereby significantly improving the signal-to-noise ratio in its various data products. In this paper, we analyzed a time series of water vapour mixing ratio observed by CARL in a well-mixed daytime boundary layer on 13 September 2005 to characterize its capability of resolving turbulent processes in the CBL. For this purpose, profiles of higher-order moments were derived including noise and sampling errors.

Our analyses confirmed that this Raman lidar system is able to observe turbulent processes present in the CBL. The noise level and resolution of the lidar's measurements allow the second moment (variance) and third moment (skewness) to be well-captured; however, the fourth moment (kurtosis) has significant uncertainty due to instrument noise. 
The accuracy of the second and third moments of the turbulence measurements is mainly limited by the sampling errors involved related to the turbulent statistics.

Accounting for the small-scale variability in water vapour (and other scalar fields) is very important for the proper modelling of the boundary layer, since not accounting for this can lead to biases in numerical simulations (Larson et al. 2001a). Larson et al. (2001b) have also shown that Gaussian probability density functions (or other two-parameter parameterizations) do not capture the variability needed by models to simulate the boundary layer, whereas three-parameter fits (e.g., those that capture the skewness of the distribution) perform much better. Water vapour variance at the top of the CBL is a key parameter in many cloud parameterizations (e.g., Bechthold et al. 1995; Price 2001; Berg and Stull 2005). The non-Gaussian variability of the water vapour, especially near the top of the CBL, may be important for the simulation of cumulus clouds in numerical models (e.g., Tompkins 2002). Thus, robust statistics of the water vapour variability in the boundary layer and its dependencies on other variables, which can be determined from the multi-year dataset collected by CARL, will be very useful to evaluate and improve boundary-layer models.

In particular, we pointed out two new analyses that can be performed using CARL data: the combination of CARL data either with measurements of the Brunt-Vaisala frequency or the vertical velocity variance for determining the moisture entrainment flux at the top of the $\mathrm{CBL}$, and the use of the vertical mixing-ratio variance profiles to estimate the moistening or drying of the CBL.

Because CARL is an operational water vapour Raman lidar (operating over $90 \%$ of the time since the upgrade in 2004), it is a suitable candidate for routine monitoring of CBL processes including the turbulent structure of the boundary layer and its dependency on other variables (e.g., the surface sensible and latent heat fluxes, and wind shear at the top of the CBL), large-scale forcing, and different scaling parameters of the CBL. These climatologies can be used for evaluating similar dependencies derived by LES and for studying parameterizations of land-surface exchange and turbulent transport in the CBL.

Acknowledgements Data used in this analysis were obtained from the Atmospheric Radiation Measurement (ARM) Program sponsored by the U.S. Department of Energy, Office of Science, Office of Biological and Environmental Research, Climate and Environmental Sciences Division. This research was partially supported by a grant DE-FG02-08ER64538 as part of the ARM program (DDT) as well as a Department of Energy Global Change Education Program fellowship (EHW). We would like to thank John Goldsmith and Bernd Mielke for their help in upgrading the detection in the Raman lidar and thus making this work possible, Rob Newsom for his efforts in processing the data from these new electronics, and Chris Martin for his diligence in the day-to-day maintenance of the system. Finally, we would like to thank Hans-Stefan Bauer for his help in generating the ECMWF map showing the synoptic conditions for our case study. We thank ECMWF for providing analyses to study the meteorological situation during the measurement period.

Open Access This article is distributed under the terms of the Creative Commons Attribution Noncommercial License which permits any noncommercial use, distribution, and reproduction in any medium, provided the original author(s) and source are credited.

\section{References}

Angevine WM, Avery SK, Ecklund WL, Carter DA (1993) Fluxes of heat and momentum measured with a boundary-layer wind profiler radar-sounding system. J Appl Meteorol 32:73-80

Bechthold P, Cuipers JWM, Mascart P, Trouilhet P (1995) Modeling of trade wind cumuli with a low-order turbulence model: toward a unified description of $\mathrm{Cu}$ and $\mathrm{Sc}$ clouds in meteorological models. J Atmos Sci 55:2666-2689

Behrendt A, Wulfmeyer V, Di Girolamo P, Kiemle C, Bauer H-S, Schaberl T, Summa D, Whiteman DN, Demoz BB, Browell EV, Ismail S, Ferrare R, Kooi S, Ehret G, Wang J (2007a) Intercomparison of water vapor data measured with lidar during IHOP_2002, Part 1: Airborne to ground-based lidar systems and 
comparisons with chilled-mirror hygrometer radiosondes. J Atmos Ocean Technol 24(1):3-21. doi:10. 1175/JTECH1924.1

Behrendt A, Wulfmeyer V, Kiemle C, Ehret G, Flamant C, Schaberl T, Bauer H-S, Kooi S, Ismail S, Ferrare R, Browell EV, Whiteman DN (2007b) Intercomparison of water vapor data measured with lidar during IHOP_2002, Part 2: Airborne to airborne systems. J Atmos Ocean Technol 24(1):22-39. doi:10.1175/JTECH1925.1

Behrendt A, Wulfmeyer V, Riede A, Wagner G, Pal S, Bauer H, Radlach M, Späth F (2009) 3-Dimensional observations of atmospheric humidity with a scanning differential absorption lidar. In Picard RH, Schäfer $\mathrm{K}$, Comeron A et al. (eds) Remote sensing of clouds and the atmosphere XIV, SPIE conference proceeding, vol 7475, Art. No. 74750L. ISBN:9780819477804. doi:10.1117/12.835143

Berg LK, Stull RB (2005) A simple parameterization coupling the convective daytime boundary layer and fair-weather cumuli. J Atmos Sci 62:1976-1988

Browning KA, Gurney RJ (eds) (1999) Global energy and water cycles. Cambridge University Press, Cambridge, 292 pp. ISBN 0-521-56057-8

Cohn SA (1995) Radar measurements of turbulent eddy dissipation rate in the troposphere: a comparison of techniques. J Atmos Ocean Technol 12:85-95

Cohn SA, Angevine WM (2000) Boundary layer height and entrainment zone thickness measured by lidars and wind-profiling radars. J Appl Meteorol 39:1233-1247

Cooper DI, Eichinger WE, Archuleta J, Hipps L, Kao J, Leclerc MY, Neale CMU, Prueger J (2003) Spatial source-area analysis of three-dimensional moisture fields from lidar, eddy covariance, and a footprint model. Agric For Meteorol 114:213-234. doi:10.1016/S0168-1923(02)00175-2

Couvreux F, Guichard F, Redelsperger J-L, Kiemle C, Masson V, Lafore J-P, Flamant C (2005) Water-vapour velocity within a convective boundary layer assessed by large-eddy simulations and IHOP_2002 observations. Q J Roy Meteorol Soc 131:2665-2693

Couvreux F, Guichard F, Masson V, Redelsperger J-L (2007) Negative water-vapour skewness and dry tongues in the convective boundary layer: observations and large-eddy simulation budget analysis. BoundaryLayer Meteorol. doi:10.1007/s10546-006-9140-y

Davis KJ, Gamage N, Hagelberg CR, Kiemle C, Lenschow DH, Sullivan PP (2000) An objective method for deriving atmospheric structure from airborne lidar observations. J Atmos Ocean Technol 17:1455-1468

Eberhard WL, Cupp RE, Healy KR (1989) Doppler lidar measurement of profiles of turbulence and momentum flux. J Atmos Ocean Technol 6:809-819

Eichinger WE, Cooper DI, Forman PR, Griegos J, Osborn MA, Richter D, Tellier LL, Thorton R (1999) The development of a scanning Raman water vapor lidar for boundary layer and tropospheric observations. J Atmos Ocean Technol 16:1753-1766

Eichinger WE, Cooper D, Kao J, Chen LC, Hipps L, Prueger J (2000) Estimation of spatially distributed latent heat flux over complex terrain from a Raman lidar. Agric For Meteorol 105:145-159. doi:10.1016/ S0168-1923(00)00183-0

Eichinger WE, Cooper DI, Hipps LE, Kustas WP, Neale CMU, Preuger JH (2006) Spatial and temporal variation of evapotranspiration using Raman lidar. Adv Water Resour 29:369-381. doi:10.1016/j.advwatres. 2005.03 .023

Ferrare RA, Turner DD, Clayton M, Schmid B, Redemann J, Covert D, Elleman R, Ogren J, Andrews E, Goldsmith JEM, Johsson H (2006) Evaluation of daytime measurements of aerosols and water vapor made by an operational Raman lidar over the Southern Great Plains. J Geophys Res 111:D05S15. doi:10. 1029/2005JD005646

Frehlich R (1997) Effects of wind turbulence on coherent Doppler lidar performance. J Atmos Ocean Technol 14:54-75

Frehlich R, Cornman L (2002) Estimating spatial velocity statistics with coherent Doppler lidar. J Atmos Ocean Technol 19:355-366

Giez A, Ehret G, Schwiesow RL, Davis KJ, Lenschow DH (1999) Water vapor flux measurements from ground-based vertically pointed water vapor differential absorption and Doppler lidars. J Atmos Ocean Technol 16:237-250

Goldsmith JEM, Balir FH, Bisson SE, Turner DD (1998) Turn-key Raman lidar for profiling atmospheric water vapor, clouds, and aerosols. Appl Opt 37:4979-4990

Gustafson WI Jr, Berg LK (2007) Implementation of the probabilistic CuP cumulus parameterization in WRF. In: 8th annual WRF user's workshop, Boulder, USA, June 11-15, 2007

Hogan RJ, Grant ALM, Illingworth AJ, Pearson GN, O’Conner EJ (2009) Vertical velocity variance and skewness in clear and cloud-topped boundary layers as revealed by Doppler lidars. Q J Roy Meteorol Soc 135:635-643. doi:10.1002/qc.413 
Kiemle C, Ehret G, Giez A, Davis KJ, Lenschow DH, Oncley SP (1997) Estimation of boundary layer humidity fluxes and statistics from airborne differential absorption lidar (DIAL). J Geophys Res 102(D24): 29189-29203

Kiemle C, Brewer WA, Ehret G, Hardesty RM, Fix A, Senff C, Wirth M, Poberaj G, LeMone MA (2007) Latent heat flux profiles from collocated airborne water vapor and wind lidars during IHOP_2002. J Atmos Ocean Technol 24:627-639

Kolmogorov AN (1941) The local structure of turbulence in incompressible viscous fluid for very large Reynolds numbers. Dokalady, ANSSSR 30:301-304

Kropfli RA (1986) Single Doppler radar measurements of turbulence profiles in the convective boundary layer. J Atmos Ocean Technol 3:305-313

Larson VE, Wood R, Field PR, Golaz J-C, Vonder Haar TH, Cotton WR (2001a) Systematic biases in the microphysics and thermodynamics of numerical models that ignore subgrid-scale variability. J Atmos Sci 58:1117-1128

Larson VE, Wood R, Field PR, Golaz J-C, Vonder Haar TH, Cotton WR (2001b) Small-scale and mesoscale variability of scalars in cloudy boundary layers: one-dimensional probability density functions. J Atmos Sci 58:1978-1994

Lenschow DH, Kristensen L (1985) Uncorrelated noise in turbulence measurements. J Atmos Ocean Technol 2:68-81

Lenschow DH, Stankov BB (1986) Length scales in the convective boundary layer. J Atmos Sci 43: 1198-1209

Lenschow DH, Mann J, Kristensen L (1994) How long is long enough when measuring fluxes and other turbulent statistics?. J Atmos Ocean Technol 11:661-673

Lenschow DH, Wulfmeyer V, Senff C (2000) Measuring second-through fourth-order moments in noisy data. J Atmos Ocean Technol 17:1330-1347

Mahrt L (1991) Boundary-layer moisture regimes. Q J Roy Meteorol Soc 117:151-176

Mann J, Lenschow DH, Kristensen L (1995) Comments on "a definite approach to turbulence statistical studies in planetary boundary layers". J Atmos Sci 52:3194-3196

Mecikalski JR, Bedka KM, Turner DD, Feltz WF, Paech SJ (2006) Ability to quantify coherent turbulent structures in the convective boundary layer using thermodynamic profiling instruments. J Geophys Res 111:D12203:1-114. doi:10.1029/2005JD006456

Moeng C-H, Wyngaard JC (1984) Statistics of conservative scalars in the convective boundary layer. J Atmos Sci 41:3161-3169

Monin AS, Yaglom AM (1971) Statistical fluid mechanics, vol 1. MIT Press, Cambridge, Mass, Mass, pp 782. ISBN-10:0-262-13062-9

Newsom RK, Turner DD, Mielke B, Clayton M, Ferrare R, Sivaraman C (2009) The use of simultaneous analog and photon counting detection for Raman lidar. Appl Opt 48:3903-3914

Pahlow M, Feingold G, Jefferson A, Andrews E, Ogren JA, Wang J, Lee Y-N, Ferrare RA, Turner DD (2006) Comparison between lidar and nephelometer measurements of aerosol hygroscopicity at the Southern Great Plains Atmospheric Radiation Measurement site. J Geophys Res 111:D05S15. doi:10. 1029/2004JD005646

Pal S, Behrendt A, Wulfmeyer V (2010) Elastic-backscatter-lidar-based characterization of the convective boundary layer and investigation of related statistics. Ann Geophys 28:825-847

Price JD (2001) A study of probability distributions of boundary-layer humidity and associated errors in parameterized cloud fraction. Q J Roy Meteorol Soc 27:739-758

Radlach M, Behrendt A, Wulfmeyer V (2008) Scanning rotational Raman lidar at $355 \mathrm{~nm}$ for the measurement of tropospheric temperature fields. Atmos Chem Phys 8:159-169

Senff C, Bösenberg J, Peters G (1994) Measurement of water vapor flux profiles in the convective boundary layer with lidar and radar-RASS. J Atmos Ocean Technol 11:85-93

Senff C, Bösenberg J, Peters G, Schaberl T (1996) Remote sensing of turbulent ozone fluxes and the ozone budget in the convective boundary layer with DIAL and radar-RASS: a case study. Contrib Atmos Phys 69:161-176

Sherlock V, Hauchecorne A, Lenoble J (1999) Methodology for the independent calibration of Raman backscatter water vapor lidar systems. Appl Opt 38:5816-5837

Sorbjan Z (1996) Effects caused by varying the strength of the capping inversion based on a large eddy simulation model of the shear-free convective boundary layer. J Atmos Sci 53:2015-2024

Sorbjan Z (2001) An evaluation of local similarity on the top of the mixed layer based on large-eddy simulations. Boundary-Layer Meteorol 101:183-207

Sorbjan Z (2005) Statistics of scalar fields in the atmospheric boundary layer based on large-eddy simulations. Part I: Free convection. Boundary-Layer Meteorol 116:467-486 
Sullivan PP, Moeng C-H, Stevens B, Lenschow DH, Mayor SD (1998) Structure of the entrainment zone capping the convective atmospheric boundary layer. J Atmos Sci 55:3042-3064

Tompkins AM (2002) A prognostic parameterization for the subgrid-scale variability of water vapor and clouds in large-scale models and its use to diagnose cloud cover. J Atmos Sci 59:1917-1942

Turner DD, Goldsmith JEM (1999) Twenty-four-hour Raman lidar water vapor measurements during the Atmospheric Radiation Measurement Program's 1996 and 1997 water vapor intensive observations periods. J Atmos Ocean Technol 16:1062-1076

Turner DD, Goldsmith JEM (2005) Refurbishment and upgrade of the ARM Raman lidar. In: Proceedings of the 15 th atmospheric radiation measurement (ARM) science team meeting, Daytona Beach, FL. Available from http://www.arm.gov/publications/proceedings/conf15/extended_abs/turner_dd1.pdf

Turner DD, Ferrare RA, Heilman LA, Brasseur LA, Feltz WF, Tooman TP (2002) Automated retrievals of water vapor and aerosol profiles from an operational Raman lidar. J Atmos Ocean Technol 19:37-50

Weckwerth TM (2000) The effect of small-scale moisture variability on thunderstorm initiation. Mon Weather Rev 128:4017-4030

Weckwerth TM, Wulfmeyer V, Wakimoto RM, Hardesty RM, Wilson JW, Banta RM (1999) NCAR-NOAA lower tropospheric water-vapor workshop. Bull Am Meteorol Soc 80:2339-2357

Weckwerth TM, Parsons DB, Koch SE, Moore JA, Lemone MA, Demoz BR, Flamant C, Geerts B, Wang J, Feltz WF (2004) An overview of the International H2O Project (IHOP_2002) and some preliminary highlights. Bull Am Meteorol Soc 85:253-277

Whiteman DN, Melfi SH, Ferrare RA (1992) Raman lidar system for the measurement of water vapor and aerosols in the Earth's atmosphere. Appl Opt 31:3068-3082

Whiteman DN et al (2006) Raman lidar measurements during the International H2O Project. Part II: Case studies. J Atmos Ocean Technol 23:170-183

Wulfmeyer V (1998) Ground-based differential absorption lidar for water-vapor and tem-perature profiling: Requirements, development, and specifications of a high-performance laser transmitter. Appl Opt 37:3804-3824

Wulfmeyer V (1999a) Investigation of turbulent processes in the lower troposphere with water-vapour DIAL and radar-RASS. J Atmos Sci 56:1055-1076

Wulfmeyer V (1999b) Investigations of humidity skewness and variance profiles in the convective boundary layer and comparison of the latter with large eddy simulation results. J Atmos Sci 56:1077-1087

Wulfmeyer V, Bösenberg J (1998) Ground-based differential absorption lidar for water-vapor profiling: Assessment of accuracy, resolution, and meteorological applications. Appl Opt 37:3825-3844

Wulfmeyer V, Feingold G (2000) On the relationship between relative humidity and particle backscattering coefficient in the marine boundary layer determined with differential absorption lidar. J Geophys Res 105(D4):4729-4741

Wulfmeyer V, Janjić T (2005) 24-h observations of the marine boundary layer using ship-borne NOAA highresolution Doppler lidar. J Appl Meteorol 44:1723-1744

Wulfmeyer V, Walther C (2001a) Future performance of ground-based and airborne water vapor differential absorption lidar. I: Overview and theory. Appl Opt 40:5304-5320

Wulfmeyer V, Walther C (2001b) Future performance of ground-based and airborne water vapor differential absorption lidar. II: Simulations of the precision of a near-infrared, high-power system. Appl Opt 40:5321-5336

Wulfmeyer V, Behrendt A, Bauer H-S, Kottmeier C, Corsmeier U, Adrian G, Blyth A, Craig G, Schumann U, Hagen M, Crewell S, Di Girolamo P, Flamant C, Miller M, Mobbs S, Richard E, Rotach M, Arpagaus A, Russchenberg H, Schlüssel P, Koenig M, Gärtner V, Steinacker R, Dorninger M, Turner DD, Weckwerth TM, Hense A, Simmer C (2008) The Convective and Orographically-induced Precipitation Study: a research and development project of the World Weather Research Program for improving quantitative precipitation forecasting in low-mountain regions. Bull Am Meteorol Soc 89(10):1477-1486. doi:10.1175/2008BAmMeteorolSoc2367.1

Wyngaard J, Brost RA (1984) Top-down and bottom-up diffusion of a scalar in the convective boundary layer. J Atmos Sci 41:102-112 